Pontifícia Universidade Católica $_{\text {man }}$

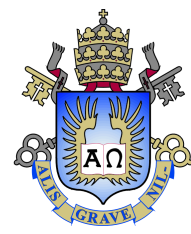

Marcos Kiehl Sonnervig

The Fiscal Theory of the Price Level with Nominal Revenues and Expenditures

Dissertation presented to the Programa de Pós-graduação em Economia of PUC-Rio in partial fulfillment of the requirements for the degree of Mestre em Economia.

Advisor : Prof. Tiago Couto Berriel

Co-Advisor: Prof. Carlos Viana de Carvalho 


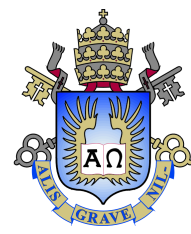

Marcos Kiehl Sonnervig

\section{The Fiscal Theory of the Price Level with Nominal Revenues and Expenditures}

Dissertation presented to the Programa de Pós-graduação em Economia of PUC-Rio in partial fulfillment of the requirements for the degree of Mestre em Economia. Approved by the undersigned Examination Committee.

\section{Prof. Tiago Couto Berriel}

Advisor

Departamento de Economia - PUC-Rio

Prof. Carlos Viana de Carvalho

Co-Advisor

Departamento de Economia - PUC-Rio

Prof. Eduardo Zilberman

Departamento de Economia - PUC-Rio

Prof. Eduardo H. de Mello Motta Loyo Banco BTG Pactual - S/A

Prof. Monica Herz

Coordenador Setorial do Centro de Ciências Sociais - PUC-Rio 
All rights reserved.

\section{Marcos Kiehl Sonnervig}

B.A., Economics, Escola de Economia de São Paulo - FGV, 2014.

Ficha Catalográfica

Kiehl Sonnervig, Marcos

The Fiscal Theory of the Price Level with Nominal Revenues and Expenditures / Marcos Kiehl Sonnervig; orientador: Tiago Couto Berriel; co-orientador: Carlos Viana de Carvalho. - 2017.

v., 52 f: il. color. ; $30 \mathrm{~cm}$

Dissertação (mestrado) - Pontifícia Universidade Católica do Rio de Janeiro, Departamento de Economia.

Inclui bibliografia

1. Economia - Teses. 2. Teoria Fiscal do Nível de Preços;. 3. Dívida Pública;. 4. Receita Pública;. 5. Despesa Pública;. 6. Nível de Preços;. 7. Inflação;. I. Berriel, Tiago Couto. II. Carvalho, Carlos Viana de. III. Pontifícia Universidade Católica do Rio de Janeiro. Departamento de Economia. IV. Título. 


\section{Acknowledgments}

I thank my advisors, Tiago Berriel and Carlos Carvalho, for their continued guidance and support throughout the past two years; Eduardo Zilberman, for all the suggestions and time spent with my thesis; My colleagues, André Sztutman, Gustavo Cicchelli and Pedro Henrique Castro, for the innumerous discussions; Eduardo Loyo, for the valuable comments and ideas.

I also thank my parents, Luis and Luciana, my brother, André, and my grandfather, Plinio, for the unconditional support. 


\section{Abstract}

Kiehl Sonnervig, Marcos; Berriel, Tiago Couto (Advisor); Carvalho, Carlos Viana de (Co-Advisor). The Fiscal Theory of the Price Level with Nominal Revenues and Expenditures . Rio de Janeiro, 2017. 52p. Dissertação de Mestrado - Departamento de Economia, Pontifícia Universidade Católica do Rio de Janeiro.

The usual assumption that fiscal policy is set in real terms is neither realistic nor innocuous. In this article, we propose a model that accounts for the existence of nominal revenues and expenditures. This creates an unexplored channel through which monetary and fiscal policies interact. We show that, in this environment, the price level can be fiscally determinate, even when all government debt is real. Also, the effects of monetary and fiscal policies are sensitive to the degree of indexation in the government budget. Using Bayesian techniques, we estimate the model for the US economy and find that the revaluation of these nominal components plays an important role as a source of fiscal financing, under a fiscally dominant regime.

\section{Keywords}

Fiscal Theory of the Price Level; Government Debt; Government Revenue; Government Expenditure; Price Level; Inflation; 


\section{Resumo}

Kiehl Sonnervig, Marcos; Berriel, Tiago Couto; Carvalho, Carlos Viana de. Receitas e Despesas nominais na Teoria Fiscal do Nível de Preços. Rio de Janeiro, 2017. 52p. Dissertação de Mestrado - Departamento de Economia, Pontifícia Universidade Católica do Rio de Janeiro.

A hipótese usual de que a política fiscal é definida em termos reais não é nem realista, nem inócua. Neste artigo, propomos um modelo que leva em consideração a existência de receitas e despesas nominais. Essa característica cria um canal inexplorado pelo qual as políticas monetária e fiscal interagem. Nós mostramos que, neste ambiente, o nível de preços pode ser fiscalmente determinado, mesmo quando toda a dívida do governo é real. Além disso, os efeitos das políticas monetária e fiscal são sensíveis ao grau de indexação no orçamento do governo. Usando técnicas de estimação Bayesiana, nós estimamos o modelo para a economia norte-americana e encontramos que a corrosão do valor real das despesas desempenha um papel importante no financiamento dos déficits do governo, sob o regime de dominância fiscal.

\section{Palavras-chave}

Teoria Fiscal do Nível de Preços; Dívida Pública; Receita Pública; Despesa Pública; Nível de Preços; Inflação; 


\section{Table of contents}

$\begin{array}{lll}1 & \text { Introduction } & 10\end{array}$

2 FTLP without Nominal Debt 12

3 Simplified Model $\quad 14$

$\begin{array}{lll}3.1 & \text { Stepping on a rake } & 16\end{array}$

4 Model $\quad 19$

4.1 Government Debt and Budget Constraint 19

4.2 Tax Revenue 20

4.3 Government Purchases and Transfers 20

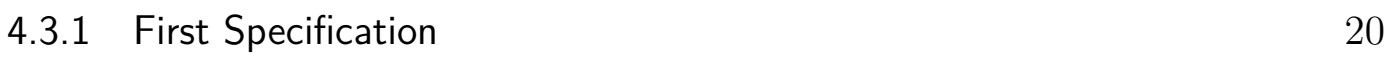

4.3.2 (Second Specification) Geometric Structure 22

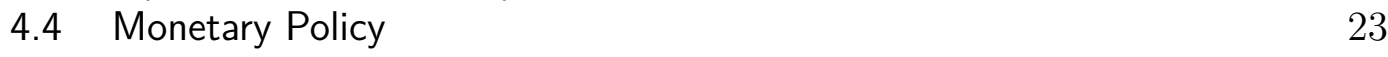

4.5 Households and Firms 24

$\begin{array}{lll}\circlearrowleft & 5 & \text { Estimation Methodology }\end{array}$

$6 \quad$ Estimation Results $\quad 29$

6.1 (1st Specification) - Estimation Results and Counterfactuals 29

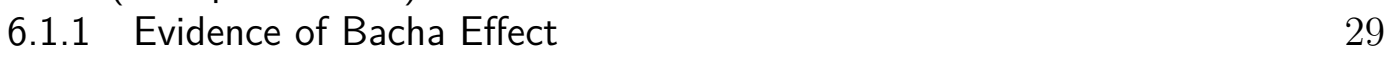

$\begin{array}{ll}6.1 .2 & \text { The role of each channel } \\ 6.2\end{array}$

6.2 Estimation Results (2nd Specification) 34

$\begin{array}{lll}7 & \text { Conclusion } & 38\end{array}$

A Proof of the Proposition $\quad 42$

A.1 Solution for the Price Level under Fiscal Regime 43

A.2 Calibration 44

B FTPL in a textbook New-Keynesian Model - Nominal vs Real debt 45

C Model Equations, Data Description and Results $\quad 47$

C.1 Model Equations (Log-Linearized) 47

C.2 Equation for the government budget constraint 49

C.3 Data Description 49

C.4 Definition of observables $\quad 51$

C.5 Estimation Results 51 


\section{List of figures}

3.1 Monetary Policy Shock - Frictionless endowment economy with real debt and non-indexed surpluses $(T<Z)$

4.1 Geometric Indexation Structure

6.1 Prior and Posterior Distributions of $\phi_{z}$

6.2 IRF Monetary Shock - Red (Dashed): $\phi_{z}=7.0 \%, \phi_{g}=1.7 \%$; Black: $\phi_{z}=\phi_{g}=0$

6.3 IRF Fiscal Shock - Red (Dashed): $\phi_{z}=7.0 \%, \phi_{g}=1.7 \%$; Black: $\phi_{z}=\phi_{g}=0$

6.4 IRF Fiscal Shock - Black: All debt is real; Red (Dashed): All debt is nominal

6.5 Prior and Posterior Distributions of $\theta_{z}$

6.6 Prior and Posterior Distributions of $\theta_{g}$

6.7 IRFs Monetary Shock - Blue (Dashed-dotted): $\theta_{z}=\theta_{g}=0.95$ Red (Dashed): $\theta_{z}=\theta_{g}=0.75$; Black: $\theta_{z}=\theta_{g}=0$

6.8 IRFs Fiscal Shock - Blue (Dashed-dotted): $\theta_{z}=\theta_{g}=0.95$ Red (Dashed): $\theta_{z}=\theta_{g}=0.75$; Black: $\theta_{z}=\theta_{g}=0$

B.1 IRF Fiscal Shock - Red (Dashed): $\lambda=1$ (Real debt); Black: $\lambda=0$ (Nominal debt)

B.2 IRF Monetary Shock - Red (Dashed): $\lambda=1$ (Real debt); Black: $\lambda=0$ (Nominal debt) 


\section{List of tables}

6.1 Inflationary effect of a fiscal shock (" $X$ "indicates the presence of a feature)

A.1 Calibration - Frictionless, Endowment Economy Model 44

B.1 Calibration NK Model 45

C.1 Estimation Results - First Specification $\quad 51$

C.2 Estimation Results - Second Specification 52 


\section{Introduction}

In monetary macroeconomic models, when the fiscal policy is explicitly modeled, it is often set in real terms - see (1), (2), (3), (4), (5), (6), for some examples. An implicit assumption in these models is the ability of the government to choose the real value of its flow variables (i.e. transfers, revenues, purchases). This assumption, however, is not realistic and, in some circumstances, is not innocuous.

An analysis of the effects of a nominal fiscal policy is developed in (7), who examines the impact of inflation on the real value of the tax revenue. The author asserts that if there are lags between a taxable event ${ }^{1}$ and the moment the government receives that payment, then changes in the price level would affect the revenue's real value (the "Tanzi Effect"). Similarly, $(8,9)$ analyse how inflation affects the real value of the government expenditure. Bacha calls attention for the fact that, if expenditures are set in nominal terms (and it is not perfectly contingent to the price level), then inflation erodes its real value (the "Bacha Effect"). This mechanism is used to explain how the Brazilian economy could have, in 1992, an inflation rate of over $1000 \%$ and a Federal deficit as low as $1.7 \%$ of the GDP.

In a more recent article, (10) analyzes, in a partial equilibrium model, the inflationary effects of a currency crises when the government chooses different ways to finance its deficits (other than a fiscal reform). As "alternative"sources of financing, the authors consider: (i) seigniorage, (ii) reduction, through inflation, of the real value of non-indexed debt and, finally, (iii) the erosion of the real value of non-indexed expenditures. Regarding this third source of financing, the authors assume that a constant fraction of the government expenditure is set in nominal terms and, therefore, have its real value permanently eroded by inflation.

In a different context, but related to the theme, (11) consider a case where the government sets an ad hoc rule for the surpluses, which reacts positively to the current inflation. The author shows that if surpluses raises linearly with inflation, then rational expectations equilibria in which inflation explodes are

\footnotetext{
${ }^{1}$ An event that creates a legal financial liability on the part of a taxpayer towards the state
} 
ruled out.

In this paper we bring these ideas to the literature on the Fiscal Theory of the Price Level (FTPL). The theory, developed in (1), (2), (4), (5) and (6), analyses the interaction between fiscal and monetary policies and recognize that the fiscal policy can be the sole determinant of the price level ((11)). Adding the possibility of nominal fiscal policy opens an unexplored channel through which fiscal and monetary policies interact. Furthermore, when inflation directly affects the real value of surpluses, some of the theory predictions can change both quantitatively and qualitatively.

Regarding our theoretical contribution, first, we show that the price level can be fiscally determinate in an economy where all government debt is real, provided that a positive fraction of surpluses are not inflation-contingent. Second, in this model, under a fiscally dominant regime, monetary policy tightening can generate a negative response of inflation in the short run (a result also existent in models with long-term nominal debt ${ }^{2}$ ).

In order to assess the role of each source of fiscal financing and to get realistic dynamics, we develop and estimate for the U.S economy a dynamic stochastic general equilibrium model where, in addition to real debt and surpluses, the government also have their nominal counterparts. We find that the role of nominal debt as a source of fiscal financing is virtually null and that, under our mean estimates, is also less relevant than the nominal components of government purchases and transfers.

The article is organized as follows: In section 2 we highlight and make a clear distinction between the different sources of fiscal financing in the FTPL; in section 3 we develop and analyse the properties of a simple model with noninflation-contingent surpluses; In section 4 we present the complete model; in section 5 we describe our estimation methodology; in section 6 we describe and analyse the results; finally, in section 7 we briefly summarize our results.

${ }^{2}$ See $(12)$ and (13) 


\section{2}

\section{FTLP without Nominal Debt}

The fiscal theory is usually seen as theory that requires the existence of nominal government debt, used as a "cushion"for fiscal imbalances. As an example of this "misperception", $(14)^{1}$ state that:

A key difference between the fiscal theory and unpleasant arithmetic [(15)] is that the former operates only in an economy with nominal government debt, whereas the latter is typically discussed under the assumption of real debt.

In fact, in the fiscal theory, the requirement that the real value of government debt matches the present value of future primary surpluses can be met by other ways rather than changes in the real value of debt. We will call these other sources of fiscal financing as "channels"through which the theory operates.

Apart from the nominal debt "cushion", a second source of fiscal financing, whose analysis is the main objective of this article, is the erosion of the real value of government expenditure - which might occur when it is set in nominal terms. The third channel is the variation of the real discount rate, which requires the existence of some form of nominal rigidity ${ }^{2}$.

Being said that, now we consider the case where the government does not have nominal debt. In this environment, the price level can be fiscally determinate, conditional on the existence of non-indexed nominal surpluses and/or nominal rigidities. In Section 3, we analyze a simple model where all government debt is real, prices are flexible and surpluses are not perfectly indexed (in the sense that inflation affects its real value). We prove the existence of a fiscal equilibrium and analyze its properties.

Another interesting case occurs when both debt and surpluses are perfectly indexed, but there is some sort of nominal rigidity (on prices and/or nominal wages). In this case, there are no revaluation effects and the price

${ }^{1}(14)$ page 14

${ }^{2}$ With long-term debt, jumps in the nominal interest rate also affects the real value government debt. 
level may still be fiscally determinate (as long as fiscal policy is active and monetary policy is passive). (16) briefly describes this situation ${ }^{3}$.

An interesting property of this equilibrium is that the revaluation effects, stressed by the fiscal theory, do not occur and, nevertheless, its main predictions do not change. For instance, in the event of a negative fiscal shock, in this equilibrium, agents raise consumption today and accept a lower future return on government real bonds. This endogenous response reduces the government cost of financing, reestablishing the fiscal solvency, without any kind of revaluation mechanism.

The existence of this equilibrium challenges the interpretation of the fiscal theory as one in which the price level, as an stock price, has its value determined by a valuation equation, which relates the expected discounted future stream of dividends (in the case of the government debt, surpluses) and the quantity of stocks (or nominal bonds) - see (6). The price level is still determined by the "intertemporal fiscal equilibrium condition", but the analogy with the stock markets loses it appeal.

In section 4 we develop a model where these three sources of fiscal financing are available and in section 6.1.2, using the estimated model, we return to this discussion analyzing, the role of each one of them.

\footnotetext{
${ }^{3}$ In section B (Appendix) we display the dynamic responses of some variables of interest to a monetary and a fiscal shock, in a textbook New-Keynesian model, with indexed debt and surpluses, under a fiscal Regime.
} 


\section{3}

\section{Simplified Model}

In this section, we present a model of a frictionless endowment economy, where $100 \%$ of government bonds are real (or perfectly indexed to inflation) and the fiscal policy has some non-indexed components. A simple way of modeling this hybrid fiscal policy rule (with indexed and non-indexed components) is:

$$
s_{t}=\left(\tau_{t}+\frac{T_{t}}{P_{t}}\right)-\left(z_{t}+\frac{Z_{t}}{P_{t}}\right)
$$

Where $s_{t}$ is the real value of surplus; $\tau_{t}$ and $z_{t}$ are the indexed components of revenue and expenditure; $T_{t}$ and $Z_{t}$ are the non-indexed components. As in (10), the nominal components are permanently eroded by inflation. In the more general case (presented in the next section), the fiscal policy may be indexed to past inflation rates and, therefore, have their values affected by inflation, only temporarily.

Under this structure, inflation directly affects the real value of surpluses. The sign of this effect, however, depends on the difference between $T_{t}$ and $Z_{t}$. In the particular case where $T_{t}=Z_{t}$, this effect is null. For simplicity, consider the case where $z_{t}, T_{t}$ and $Z_{t}$ are constant:

$$
s_{t}=\left(\tau_{t}+\frac{T}{P_{t}}\right)-\left(z+\frac{Z}{P_{t}}\right)
$$

In this simplified model, the Government has only real debt. Its flow budget constraint is:

$$
b_{t}=R_{t-1}^{r} b_{t-1}-s_{t}
$$

Where $R_{t-1}^{r}$ is the bond's real return, $b_{t}$ is value of debt and $s_{t}$ is the real value of the surplus, in period $t$.

The fiscal authority sets a rule for the indexed component of the revenue and other three constants (The nominal component of revenue and transfers, plus the real component of transfers):

Where, $\tau$ and $b$ are the steady-state levels of $\tau_{t}$ and $b_{t} . \epsilon_{t}^{t}$ represents an exogenous fiscal policy shock.

The representative agent receives an endowment $y$ every period and solve: 


$$
\begin{aligned}
& \max _{\left\{c_{t}, b_{t}\right\}_{t=0}^{t=0}} E_{t} \sum_{j=0}^{\infty} \beta^{t+j} \frac{C_{t+j}^{(1-\sigma)}}{1-\sigma} \\
& \text { s.t. } \quad C_{t}+b_{t}+s_{t} \leq y+R_{t-1}^{r} b_{t-1}
\end{aligned}
$$

The monetary authority controls the interest rate of a nominal bonds, which satisfies a non-arbitrage relation with the real bonds, and follows a standard Taylor rule:

$$
R_{t}=\frac{1}{\beta}\left(\frac{P_{t}}{P_{t-1}}\right)^{\phi_{\pi}} \epsilon_{t}^{M}
$$

The equilibrium in this model is defined as an initial debt stock $b_{-1}$, a sequence of prices $\left\{P_{t}, R_{t}^{r}, R_{t}\right\}$ and allocations $\left\{C_{t}, b_{t}, \tau_{t}, z, T, Z\right\}$ satisfying the individual optimality condition and the market clearing conditions. The proposition that follows establishes the conditions for the existence of a unique bounded equilibrium.

Proposition: If the nominal component of revenues has a different value than the nominal component of expenditure, $(Z \neq T)$ then, as in (1), there are two disjoint regions of the parametric space with a locally unique bounded equilibrium:

Region 1 (Monetary Regime): $\left|\phi_{\pi}\right|>1$ and $\left|\frac{1}{\beta}-\phi_{b}\right|<1$

Region 2 (Fiscal Regime): $\left|\phi_{\pi}\right|<1$ and $\left|\frac{1}{\beta}-\phi_{b}\right|>1$

Proof in the Appendix (Section A).

The first thing worth noting here is that, although the government does not have nominal bonds, there is the possibility of a fiscally dominant regime (Regime F). Therefore, in this case, the Fiscal Theory of the Price Level (FTPL) operates through the "revaluation" of the government's net transfers. This point is informally made in (17).

There are interesting theoretical features of the equilibrium in regime F. As stressed in the literature of the FTPL, under this regime, the price level is determined by the government's intertemporal budget constraint (or "government debt valuation equation", (6)). In this case, a negative fiscal shock $(\Delta s<0)$ results in a higher inflation, which revalues real value of the government debt. The same happens here, if the non-indexed expenditure is larger than the non-indexed revenue $(T<Z)$. In this case, a negative fiscal shock is "financed"by the erosion of the real value of government expenditure. This fiscal effect of inflation also resembles, in an stylized fashion, the "Bacha effect". 
To understand this result, it is worth considering the government debt valuation equation:

$$
b_{t-1}=\sum_{j=0}^{\infty} \beta^{j} E_{t}\left\{\tilde{\tau}_{t+j}-\frac{Z_{t+j}-T_{t+j}}{P_{t+j}}\right\}
$$

Where $\tilde{\tau}_{t} \equiv \tau_{t}-z_{t}$ and $V_{t} \equiv Z_{t}-T_{t}$. Rearranging the terms, the equation can be rewritten as:

$$
b_{t-1}+\frac{\sum_{j=0}^{\infty} Q_{t}(t+j) E_{t}\left[V_{t+j}\right]}{P_{t}}=\sum_{j=0}^{\infty} \beta^{j} E_{t} \tilde{\tau}_{t+j}
$$

For simplicity, consider the case of a pegged nominal interest rate $\phi_{\pi}=0$. Also, since $E_{t}\left[V_{t+j}\right]=V$, in this example, this equation can be even more simplified:

$$
b_{t-1}+\frac{V}{1-\beta} \frac{1}{P_{t}}=\sum_{j=0}^{\infty} \beta^{j} E_{t} \tilde{\tau}_{t+j}
$$

If $(T<Z)$, then $V>0$ and, therefore, the government net transfers works exactly as a nominal debt "cushion".

In this model, since the only source of fiscal financing is the "erosion"of the real value of the fiscal variables, an awkward prediction occurs when the revenue of the government is less indexed than the expenditure $(T>Z)$. In this case, as inflation reduces the real value of surpluses, a negative fiscal shock generates deflation. If however, the government has a sufficiently large stock of nominal debt, then the negative fiscal shock generates a positive response of inflation (as predicted by standard models), which, through the "asymmetry" $(T>Z)$, reinforces the fiscal shock, generating even higher inflation rates ${ }^{1}$.

\section{1}

\section{Stepping on a rake}

The effects of a monetary policy shock also changes under this circumstances. A standard result in the FTPL literature is the rise of inflation following a monetary tightening. In contrast with that prediction, here, if $(T<Z)$, the monetary policy shock has a negative impact over

${ }^{1}$ If revenue is less indexed than expenditure $(T>Z)$, for sufficiently large values of nominal debt, the inflation response for a negative fiscal shock $(\Delta s<0)$ is positive. However, starting from the case where $100 \%$ of debt is Nominal, there is a discontinuity on the inflation response as debt gets more indexed: If a small fraction of debt gets indexed, the response is amplified, but if a large fraction gets indexed, than the response inverses and the shocks generates deflation. In this model, the discontinuity occurs when $B_{t-1}=(Z-T) /(1-\beta)$ - the nominal value of debt equals the present value of the difference between the nominal components of transfers and revenues 
inflation in the short run. In the long-run, however, prices are higher than it was before the shock. Figure 3.1 displays the dynamic responses of some variables of interest to a monetary policy shock that takes the form of a positive realization of $\epsilon_{t}^{M}=1^{2}$.
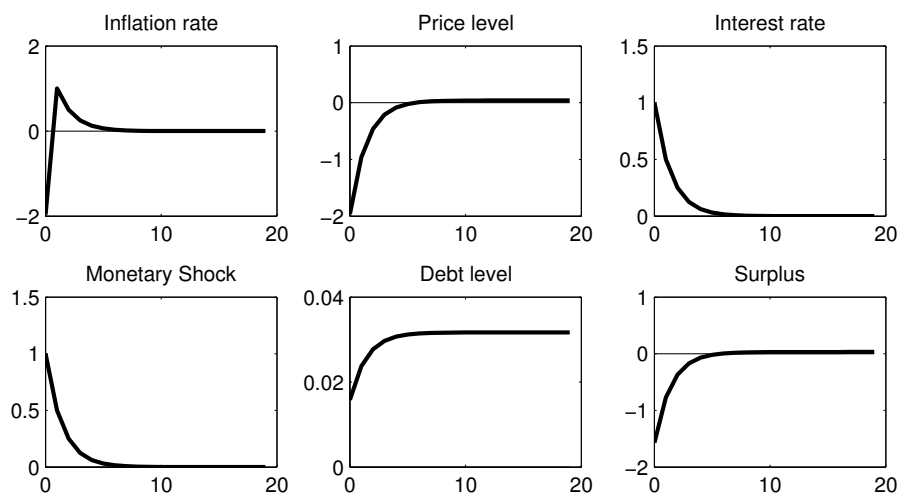

Figure 3.1: Monetary Policy Shock - Frictionless endowment economy with real debt and non-indexed surpluses $(T<Z)$

This result is also easily understood through the debt valuation equation:

$$
b_{t-1}+\frac{\sum_{j=0}^{\infty} Q_{t}(t+j) E_{t}\left[V_{t+j}\right]}{P_{t}}=\sum_{j=0}^{\infty} \beta^{j} E_{t} \tilde{\tau}_{t+j}
$$

Where $Q_{t}(t+j)$ is equal to the inverse of the nominal bond return from period $t$ to $t+j$. Now the result can be clearly described: the interest rate rise have a negative effect on bond prices $\left(Q_{t}(t+j)\right)$ reducing the present value of the nominal government expenditures and, hence, generating a negative wealth effect on private agents. The effect on price level can be rationalized as following: the negative wealth effect reduces demand for goods, which, in a flex-price economy, translates, immediately, in a reduction of the price level. Also, the price response is proportional to the change in the present value of nominal expenditures $\left(\sum_{j=0}^{\infty} Q_{t}(t+j) E_{t}\left[V_{t+j}\right]\right)$. Finally, since the real value of net transfers is permanently eroded, the debt level changes to a higher steadystate level.

The same result occurs in an economy with long-term nominal debt and indexed surpluses. (12) and (13) analyse this case. In (12) words:

After initially dropping, the inflation rate rises back above its steady state level by as much as it initially fell, and the rise is more sustained than the initial drop. This is the "stepping on a rake"

\footnotetext{
${ }^{2}$ The $\log$-linearized equations and the parameters calibration are described in the Appendix (Sections A and A.2)
} 
phenomenon: Apparently effective measures to reduce inflation come back, after a delay, to produce precisely the opposite of the desired effect. 


\section{Model}

In this section, we propose a model where the government has a more complete debt structure and the indexation rule takes different forms. We incorporate this fiscal side in a medium-scale DSGE model based on (18), which, in turn, is based on (19), (20) and (21).

\section{1}

\section{Government Debt and Budget Constraint}

The government issues one-period indexed bonds and nominal bonds of all maturities. For simplicity, we assume that the maturity structure declines at a constant rate $\rho$, as in (5). Hence, the government flow budget constraint is:

$$
P_{t} b_{t-1}^{r}+B_{t-1}^{m}\left[1-\sum_{j=1}^{\infty} Q_{t}(t+j) \rho^{j}\right]=P_{t} s_{t}+P_{t} Q_{t}^{r} b_{t}^{r}+B_{t}^{m} \sum_{j=1}^{\infty} Q_{t}(t+j) \rho^{j-1}
$$

Where $\rho^{j-1} B_{t}^{m}$ and $Q_{t}(t+j)$ are, respectively, the quantity and the price of a nominal bond that matures in $t+j . b_{t}^{r}$ and $Q_{t}^{r}$ are, respectively, the quantity and price of the indexed bond.

I also assume that government supply of the real bonds is a constant fraction of the total supply of bonds $\left(b_{t}^{r}+B_{t}^{m} / P_{t}\right)$.

$$
b_{t}^{r}=\alpha \frac{B_{t}^{m}}{P_{t}}
$$

The real value of the government surplus has three components:

$$
\begin{aligned}
& s_{t}=T_{t}-g_{t}-z_{t} \\
& T_{t}, g_{t} \geq 0, \text { and } z_{t} \in \mathbb{R}
\end{aligned}
$$

Where $T_{t}$ is its revenues from distortionary taxes, $g_{t}$ is the real value of its purchases and $z_{t}$ is the real value of its net transfers. 


\section{2}

\section{Tax Revenue}

The tax revenue is:

$$
T_{t}=\tau_{t}\left(R_{t}^{k} K_{t}+W_{t} L_{t}\right)
$$

$K_{t}$ and $R_{t}^{k}$ represents, respectively, aggregate effective capital and its return. $W_{t}$ and $L_{t}$ represents, respectively, the real wage and the labor supply. Note that the same tax rate $\tau_{t}$ is applied to both the labor income and wage income. This specification is based on (21).

The tax rate for capital and labor respond to the lagged debt-to-output ratio $\left(\hat{d}_{t-1}^{m} \equiv \frac{B_{t-1}^{m} / P_{t-1}}{Y_{t-1}}\right)$ according to the following rule:

$$
\tau_{t}=\rho_{\tau} \tau_{t-1}+\left(1-\rho_{\tau}\right) \gamma_{\tau} \hat{d}_{t-1}^{m}+\epsilon_{t}^{\tau}, \epsilon_{t}^{\tau} \sim N\left(0, \sigma_{\tau}^{2}\right)
$$

\section{3}

\section{Government Purchases and Transfers}

A general structure for the indexation of fiscal instruments can be represented as an infinite sum of terms involving past values of the price level:

$$
\begin{aligned}
Z_{t} & =z_{1, t} P_{t}+z_{2, t} P_{t-1}+z_{3, t} P_{t-2}+\ldots \\
& =\sum_{j=1}^{j=\infty} z_{j, t} P_{t-j+1}
\end{aligned}
$$

The usual indexation structure of most monetary models is the particular form whereby $z_{j, t}=0$ for all $j>1$. In this case, $Z_{t}=z_{1, t} P_{t}$ (is perfectly indexed to the price level). This general form for modeling the indexation structure is completely characterized by the terms $z_{j, t}$, which are functions potentially involving any other real variable from the system.

In order to estimate this structure, we impose two sets of restrictions, defining, therefore, two different specifications. The first one sets $z_{j, t}=0$ for all $j$, with the exception of $j=1$ and $j=t$. The resulting model is very similar to the case analyzed in the last section. The second one imposes an geometrically decaying structure. They are described in detail in the following sections.

\subsection{1}

\section{First Specification}

As in the simple model described in the last section, we assume that the government net transfers have two different forms of indexation rules. The 
first one captures the standard type of indexation of the literature - the case whereby the fiscal rule is inflation-contingent. The second one captures the most dramatic case whereby there are no indexation at all. Finally, there is an exogenous component that represents unexpected transfers shocks.

$$
\begin{aligned}
z_{t} & =\left(z^{+}+\frac{Z^{+}}{P_{t}}\right)-\left(z^{-}+\frac{Z^{-}}{P_{t}}\right)+\eta_{t}^{z} \\
\eta_{t}^{z} & =\rho_{z} \eta_{t-1}^{z}+\epsilon_{t}^{z} \quad, \epsilon_{t}^{z} \sim N\left(0, \sigma_{z}^{2}\right)
\end{aligned}
$$

The term $\left(z^{-}+\frac{Z^{-}}{P_{t}}\right)$ can be interpreted as lump-sum taxes. Defining $\equiv\left(z^{+}-z^{-}\right)$and $V_{2, t} \equiv\left(Z_{t}^{+}-Z_{t}^{-}\right)$, the real value of transfers can be written as:

$$
z_{t}=\left(v_{1, t}+\frac{V_{2, t}}{P_{t}}\right)+\eta_{t}^{z}
$$

As in last section's model, $V_{2, t}$ can be either negative or positive. This implies that inflation can have a positive or a negative impact on the real value of transfers and, therefore, on surpluses. For simplicity, we assume that $V_{2, t}$ and $v_{1, t}$ are constants. The log-linearized equation for the net transfers is ${ }^{1}$ :

$$
\hat{z}_{t}=-\underbrace{\left(\frac{V_{2} / P}{z}\right)}_{\phi_{z}} \hat{p}_{t}+\eta_{t}^{z}
$$

The distribution of the parameter $\phi_{z} \in[-1,1]$ is estimated and used to gauge, first, the sign of the effect of inflation on net transfers and, second, the fraction of the net transfers that are not indexed to the price level.

The government purchases have the same indexation structure:

$$
\begin{aligned}
& G_{t}=G_{1, t}+G_{2}+P_{t} \eta_{t}^{g} \\
& G_{1, t}=g_{1, t} P_{t} \\
& \eta_{t}^{g}=\rho_{g} \eta_{t-1}^{g}+\epsilon_{t}^{g} \quad, \epsilon_{t}^{g} \sim N\left(0, \sigma_{g}^{2}\right)
\end{aligned}
$$

Its real value is, therefore:

$$
g_{t}=g_{1, t}+\frac{G_{2}}{P_{t}}+\eta_{t}^{g}
$$

I assume that the indexed component $\left(g_{1, t}\right)$ respond to the lagged debt${ }^{1}$ The $\log$ deviations of a variable $X_{t}$ from its steady state $X$ is defined as $\hat{x}$. 
to-output ratio $\left(\hat{d}_{t-1}^{m} \equiv \frac{B_{t-1}^{m} / P_{t-1}}{Y_{t-1}}\right)$ according to the following rule:

$$
g_{1, t}=-\left[1-\left(\frac{G_{2} / P}{g}\right)\right]^{-1} \gamma_{g} d_{t-1}^{m}
$$

The term $\left[1-\left(\frac{G_{2} / P}{g}\right)\right]^{-1}$ multiplying the reaction parameter $\gamma_{g}$ is included to make sure the reaction function does not depend on the indexation structure.

The log-linearized equation for the government purchases is:

$$
\hat{g}_{t}=-\gamma_{g} \hat{d}_{t-1}^{m}-\underbrace{\left(\frac{G_{2} / P}{z}\right)}_{\phi_{g}} \hat{p}_{t}+\eta_{t}^{g}
$$

\subsection{2}

\section{(Second Specification) Geometric Structure}

In this second specification we allow the fiscal variables to be indexed to past inflation values and impose a geometric decaying weight to the indexation structure:

$$
\begin{aligned}
& Z_{t}=z\left(1-\theta_{z}\right)\left[P_{t}+\theta_{z} P_{t-1}+\theta_{z}^{2} P_{t-2}+\ldots\right]+P_{t} \eta_{t}^{z} \\
& \eta_{t}^{z}=\rho_{z} \eta_{t-1}^{z}+\epsilon_{t}^{z} \quad, \epsilon_{t}^{z} \sim N\left(0, \sigma_{z}^{2}\right)
\end{aligned}
$$

Here, $z$ is equal to the steady-state level of government real net transfers and $\theta_{z} \in[0,1]$ is the parameter that defines the indexation structure. Note that the two polar cases of the first specification are also contemplated here: if $\theta_{z}=0$, than $Z_{t}=z P_{t}+\eta_{t}^{z} P_{t}$ is perfectly indexed to inflation. Also, if $\theta_{z}=1$, then $Z_{t}=P_{-1} z+\eta_{t}^{z}$, which is exactly the case where there is no indexation at all ${ }^{2}$. Moreover, under this specification, for all values of $\theta_{z}$ different from 1 , inflation affects the real value o transfers only temporarily, as opposed to the first specification, where the effect is permanent.

As an example, Figure 4.1 left panel depicts how weights are distributed into the past price levels and the right panel represents the cumulative indexation. The blue bars represent the case whereby $\theta_{z}=0.5$ and the red bars when $\theta_{z}=0.75$. When $\theta_{z}=0.5$, after one period, $75 \%$ of the total transfers

\footnotetext{
${ }^{2}$ The two specifications are equivalent if $\theta_{z}=1$ and $\phi_{z}=1$ (no indexation at all); and also if $\theta_{z}=0$ and $\phi_{z}=0$ (perfect indexation)
} 
have already had their nominal values readjusted whereas when $\theta_{z}=0.75$ it takes 4 periods for the same fraction of the transfers to be readjusted.
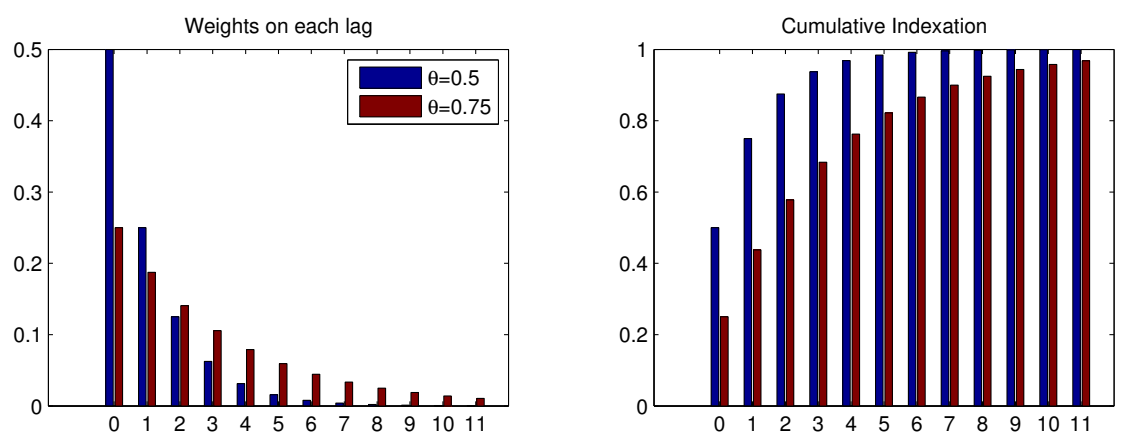

Figure 4.1: Geometric Indexation Structure

The government purchases have the same indexation structure, but it also respond to the debt level:

$$
\begin{aligned}
& G_{t}=g\left(1-\theta_{g}\right)\left[P_{t}+\theta_{g} P_{t-1}+\theta_{g}^{2} P_{t-2}+\ldots\right]+P_{t}\left(-\gamma_{g} d_{t-1}^{m}+\eta_{t}^{g}\right) \\
& \eta_{t}^{g}=\rho_{g} \eta_{t-1}^{g}+\epsilon_{t}^{g} \quad, \epsilon_{t}^{g} \sim N\left(0, \sigma_{g}^{2}\right)
\end{aligned}
$$

To simulate/estimate the model we write the geometric structure in a recursive way, using auxiliary variables $v_{g}$ and $v_{z}$. The log-linearized equations for the real value of transfers and purchases are:

$$
\begin{aligned}
& \hat{z}_{t}=v_{z, t}+\eta_{t}^{z} \\
& v_{z, t}=\theta_{z}\left(v_{z, t-1}-\pi_{t}\right) \\
& \hat{g}_{t}=v_{g, t}-\gamma_{g} \hat{d}_{t-1}^{m}+\eta_{t}^{g} \\
& v_{g, t}=\theta_{g}\left(v_{g, t-1}-\pi_{t}\right)
\end{aligned}
$$

\section{4}

\section{Monetary Policy}

Regarding the monetary policy, we assume a simple Taylor rule of the form:

$$
\hat{R}_{t}=\rho_{r} \hat{R}_{t-1}+\left(1-\rho_{r}\right)\left(\phi_{\pi} \hat{\pi}_{t}+\phi_{y} \hat{Y}_{t}\right)+\epsilon_{t}^{r}, \quad \epsilon_{t}^{r} \sim N\left(0, \sigma^{r}\right)
$$

The rest of the model is quite standard and it is based on (18). We describe the private sector of the model in the next subsection. 


\section{5}

\section{Households and Firms}

\section{Firms}

The production in this economy is made by a final goods producer and an intermediate good producer. The perfectly competitive final goods producer uses a continuum of intermediate goods $y_{t}(i)$, according to the constant returnto-scale technology as in (22):

$$
\left[\int_{0}^{1} y_{t}(i)^{1 /\left(1+\eta_{t}^{p}\right)} d i\right]^{\left(1+\eta_{t}^{p}\right)} \geq Y_{t}
$$

where $\eta_{t}^{p}$ is the exogenous time-varying markup to the intermediate goods' price.

The final goods producer chooses $Y_{t}$ and $y_{t}(i)$ to maximize profit subject to the technology. The demand for $y_{t}(i)$ is given by:

$$
y_{t}(i)=Y_{t}\left(\frac{p_{t}(i)}{P_{t}}\right)^{-\left(1+\eta_{t}^{p}\right) / \eta_{t}^{p}}
$$

Where $\left(1+\eta_{t}^{p}\right) / \eta_{t}^{p}$ is the elasticity of substitution between the intermediate goods.

The intermediate goods producers are monopolistic competitors in their product market. Firm $i$ produces by a Cobb-Douglas technology:

$$
y_{t}(i)=A_{t}^{1-\alpha} k_{t}^{\alpha}(i) L_{t}(i)^{1-\alpha} .
$$

Where $A_{t}$ is a permanent shock to technology and its growth rate, $a_{t}=$ $\ln A_{t}-\ln A_{t-1}$, follows a stationary $\mathrm{AR}(1)$ process:

$$
a_{t}=\left(1-\rho_{a}\right) \gamma+\rho_{a} a_{t-1}+\epsilon_{t}^{a} \quad, \epsilon_{t}^{a} \sim N\left(0, \sigma_{a}^{2}\right)
$$

Where $\gamma$ is the steady-state growth rate.

The model has a price stickiness a la (23). The intermediate firms have a probability of $\left(1-\omega_{p}\right)$ each period to reset their prices. Those cannot do so index their prices to past inflation according to the rule:

$$
p_{t}(i)=p_{t-1}(i) \pi_{t-1}^{\chi^{p}} \pi^{1-\chi^{p}}
$$

\section{Labor packers}

A labor packer, in a perfectly competitive market, purchases a continuum of differentiated labor inputs $L_{t}(j)$ from the households and gather them to produce a composite labor service $L_{t}$ by the technology:

$$
L_{t}=\left[\int_{0}^{1} L_{t}(i)^{1 /\left(1+\eta_{t}^{w}\right)} d j\right]^{\left(1+\eta_{t}^{w}\right)},
$$


where $\eta_{t}^{w}$ denotes a time-varying exogenous markup to wages. Its demand function is:

$$
L_{t}(i)=L_{t}\left(\frac{W_{t}(j)}{W_{t}}\right)^{-\left(1+\eta_{t}^{w}\right) / \eta_{t}^{w}}
$$

Where $W_{t}(j)$ is the wage receive from the labor packer by the household $j$ and $W_{t}$ is the wage for the composite labor service paid by intermediate firms.

\section{Households}

Each household maximizes its discounted utility subject to its budget constraint:

$$
E_{t} \sum_{s=0}^{\infty} \beta^{s} u_{t+s}^{b}\left[\ln \left(C_{t+s}-\theta C_{t+s-1}\right)-\frac{\phi L_{t+s}(j)^{1+\nu}}{1+\nu}\right]
$$

where $\beta \in(0,1)$ is the discount factor, $\theta \in(0,1)$ is external habit formation, $\nu \geq 0$ is the inverse of the Frisch labor elasticity and $\varphi$ is the disutility weight on labor. Each household owns one unit of specialized labor $L(j)$ and sets its wage in that market. $u_{t}^{b}$ represents a stochastic component of the preference and it follows a $\operatorname{AR}(1)$ :

$$
\ln u_{t}^{b}=\left(1-\rho^{b}\right) \ln u^{b}+\rho^{b} \ln u_{t-1}^{b}+\epsilon_{t}^{b}, \quad \epsilon_{t}^{b} \sim N\left(0, \sigma_{b}^{2}\right)
$$

The household flow budget constraint is:

$$
\begin{aligned}
& P_{t} b_{t-1}^{r}+B_{t-1}^{m}\left[1-\sum_{j=1}^{\infty} Q_{t}(t+j) \rho^{j}\right]+D_{t}+ \\
&\left(1-\tau_{t}\right) W_{t}(j) L_{t}(j)+\left(1-\tau_{t}\right) R_{t}^{k} \nu_{t} \bar{K}_{t-1}-\psi\left(\nu_{t}\right) \bar{K}_{t-1}= \\
& C_{t}+I_{t}+P_{t} s_{t}+P_{t} Q_{t}^{r} b_{t}^{r}+B_{t}^{m} \sum_{j=1}^{\infty} Q_{t}(t+j) \rho^{j-1}
\end{aligned}
$$

Each household owns an equal share of all intermediate firms and receives the share $D_{t}$ of intermediate firms profits. Also, the households control both the size of the capital stock and its utilization rate $v_{t}$. Effective capital, $k_{t}=v_{t} \bar{k}_{t-1}$ is rented to firms at the rate $R_{t}^{k}$. The cost of capital utilization is $\psi\left(v_{t}\right)$ per unit of physical capital. In the steady state, $v=1$ and $\psi(1)=0$. Define a parameter $\psi \in[0,1)$ such that $\psi^{\prime \prime}(1) / \psi^{\prime}(1) \equiv \psi / 1-\psi$. Then, the law of motion for private capital is:

$$
\bar{k}_{t}=(1-\delta) \bar{k}_{t-1}+u_{t}^{i}\left[1-s\left(\frac{i_{t}}{i_{t-1}}\right)\right] i_{t}
$$

Where $s\left(i_{t} / i_{t-1}\right)$ is the adjustment cost as in (20) and (19). By assumption, $s(\gamma)=s^{\prime}(\gamma)=0$ and $s^{\prime \prime}(\gamma)=s>0$. The term $u_{t}^{i}$ captures exogenous variations in the efficiency with which investment can be transformed into 
physical capital, as in (24). It follows an AR(1) process:

$$
\ln u_{t}^{i}=\left(1-\rho^{i}\right) \ln u^{i}+\rho^{i} \ln u_{t-1}^{i}+\epsilon_{t}^{i}, \quad \epsilon_{t}^{i} \sim N\left(0, \sigma_{i}^{2}\right)
$$

In each period a fraction $1-\omega_{w}$ households are allowed to re-optimize their wage rate by maximizing:

$$
E_{t}\left[\sum_{s=0}^{\infty}\left(\beta \omega_{w}\right)^{s} u_{t+s}^{b} U\left(C_{t+s \mid t}, L_{t+s \mid t}\right)\right]
$$

Subject to their budget constraint (Eq.??) and the labor demand function (Eq. 4-17). Those who cannot reset their wages, adjust their values according to the following rule:

$$
W_{t}(j)=W_{t-1}(j)\left(\pi_{t-1} e^{a_{t-1}}\right)^{\chi^{w}}+\left(\pi e^{\gamma}\right)^{\left(1-\chi^{w}\right)}
$$




\section{5}

\section{Estimation Methodology}

In the estimation, we use quarterly data for three samples: 1955Q1-1966Q4, 1967Q1-1979Q2 and 1984Q1-2007Q4 - the same data used in (18). (25), in a regime switching model, find evidence of changes in policy parameters between these three periods, motivating the cutoffs. The period of 1967Q1-1979Q2, known as the "Great Inflation", is characterized by fast economic growth and high inflation. It ended with the appointment of Paul Volcker as chairman of the FED board, in August 1979. The third period, known as the "Great Moderation"is characterized by low inflation and low volatility in macroeconomic aggregates.

I use nine time series in the estimation: consumption, investment, wages, government spending, tax revenue, government debt, hours worked, inflation and interest rate:

$$
\left[\begin{array}{c}
\text { dlCons }_{t} \\
\text { dlInv }_{t} \\
\text { dlWage }_{t} \\
\text { dlGovSpend }_{t} \\
\text { dlTaxRev }_{t} \\
\text { dlGovDebt }_{t} \\
\text { lHous }_{t} \\
\text { lInfl }_{t} \\
\text { IFedFunds }_{t}
\end{array}\right]=\left[\begin{array}{c}
100 \gamma \\
100 \gamma \\
100 \gamma \\
100 \gamma \\
100 \gamma \\
100 \gamma \\
0 \\
0 \\
0
\end{array}\right]+\left[\begin{array}{c}
\hat{c}_{t}-\hat{c}_{t-1}+\hat{a}_{t} \\
\hat{i}_{t}-\hat{i}_{t-1}+\hat{a}_{t} \\
\hat{w}_{t}-\hat{w}_{t-1}+\hat{a}_{t} \\
\hat{g}_{t}-\hat{g}_{t-1}+\hat{a}_{t} \\
\hat{t}_{t}-\hat{t}_{t-1}+\hat{a}_{t} \\
\hat{b}_{t}-\hat{b}_{t-1}+\hat{a}_{t} \\
\hat{L}_{t} \\
\hat{\pi}_{t} \\
\hat{R}_{t}
\end{array}\right]
$$

Where 1 and $\mathrm{dl}$ represents 100 times the $\log$ and the log difference of each variable. The small letters represent the transformed quantity of a level variable: $\hat{b}_{t}$ is the transformed real debt level, $\hat{a}_{t}$ is the percentage deviation of technology growth rate from the steady-state growth rate $\gamma$. In the appendix (Section C.3) we provide a detailed description of the data.

Using the software Dynare, and based on (26) and (27), first, we use the minimization routine csminwel.m (by Prof Christopher Sims) to search for a local minimum of the negative $\log$ posterior function. This value is used 
to initialize the estimation. The posterior distribution is estimated using the random walk Metropolis-Hastings algorithm. We perform, for each estimation, two chains of 2 million draws of the posterior distribution. We discard the first half of the draws at the end of the estimation, leaving us with a final sample size of 1 million. Diagnostic tests implemented in Dynare are perfomed to ensure convergence of the MCMC chains.

Using (28) methodology, we find that all the estimated parameters are locally identified. Some of the parameters, however, are calibrated. As in (18), the discount factor $\beta$ is set to 0.99 . The capital income share $\alpha$ is set to 0.3 , which implies a labor share of 0.7 . The quarterly depreciation rate for capital, $\delta$, is set to 0.025 , implying the annual depreciation rate of $10 \% . \eta^{w}$ and $\eta^{p}$ are set to 0.14 , so the steady-state markups in the product and labor markets are $14 \%$. We use the mean values of data from 1955Q1 to 2007Q4 to calibrate the fiscal variables. The tax rate is set to 0.185 , the ratio of government spending to output is set to 0.104 and the ratio of government debt to annual output is set to 0.348. Since the Treasury Inflation-Protected Securities (or TIPS) were introduced only in $1997^{1}$, the parameter $\lambda$ (share of indexed debt on total debt) is set to zero. The parameter $\rho$ is calibrated, so the average maturity of nominal debt is equal to 43 months. Also, when computing these statistics from the data, output is defined as the sum of consumption, investment, and government consumption and investment, consistent with the output definition in the model.

For each sample, we estimate the model with the two different specifications for the indexation structure. Therefore, there are a total of six estimations.

Regarding the monetary and fiscal policy parameters $\left(\phi_{\pi}, \phi_{y}, \gamma_{\tau}\right.$ and $\left.\gamma_{g}\right)$, in all estimations, we set our prior for these policy parameters with a distribution centered in Regime M. As in (20), for $\phi_{\pi}$, we set a normal distribution with mean 1.5 and standard deviation of 0.25 ; for $\phi_{y}$, a normal distribution with mean 0.25 and standard deviation of 0.05 . As in (18), for $\gamma_{\tau}$ and $\gamma_{g}$ we set a normal distribution with means, respectively, of 0.15 and 0.05 , and standard deviation of 0.05 .

The table with the complete set of priors and posterior estimates is in the Appendix (Section C.5).

\footnotetext{
${ }^{1}$ https://www.treasurydirect.gov/indiv/research/indepth/tips/res_tips.htm
} 


\section{6 \\ Estimation Results}

Regarding the posterior distribution, the mean estimates for the standard parameters are close to the estimates of (20) - See appendix. The posterior distribution for the fiscal parameters are also close to the estimation in (18).

\section{1}

\section{(1st Specification) - Estimation Results and Counterfactuals}

\subsection{1}

\section{Evidence of Bacha Effect}

As discussed in the model's section, the government net transfer is modeled as:

$$
z_{t}=\left(z_{t}^{+}+\frac{Z^{+}}{P_{t}}\right)-\left(z_{t}^{-}+\frac{Z^{-}}{P_{t}}\right)+\eta_{t}^{z}
$$

The parameter $\phi_{z} \equiv \frac{\left(Z^{+}-Z^{-}\right) / P}{z}$ is a measure of the non-indexed fraction of the government net transfers. If it is positive, than an inflation rise has a negative impact on the real value of transfers. In the model, this happens when the size of the government nominal transfers is greater than the size of the government nominal lump-sum taxes $\left(Z^{+}>Z^{-}\right)$.

I set a Normal distribution with zero mean and standard deviation $\sigma=0.1$ as the prior for this parameter. A priori, therefore, there is equal probability of having a negative or a positive sign. As shown in Figure 6.1 The posterior distribution for this parameter have mean in the positive region, in all three periods of the sample (1955Q1-1966Q4, 1967Q1-1979Q2 and 1984Q1-2007Q4). Moreover, since the revenue from distortive taxes is perfectly indexed, $\phi_{z}>0$ implies that inflation has a positive impact over the real surpluses (the "Bacha effect").

When interpreting this results, it is important to note that, in the estimation, we use data for government purchases, revenue and debt level. As a result, the variable $\hat{z}_{t}$ is linked to the residual of government flow budget constraint. In this case, what we call as "net transfers"actually captures anything that affects the debt level other than revenue and expenditure. 

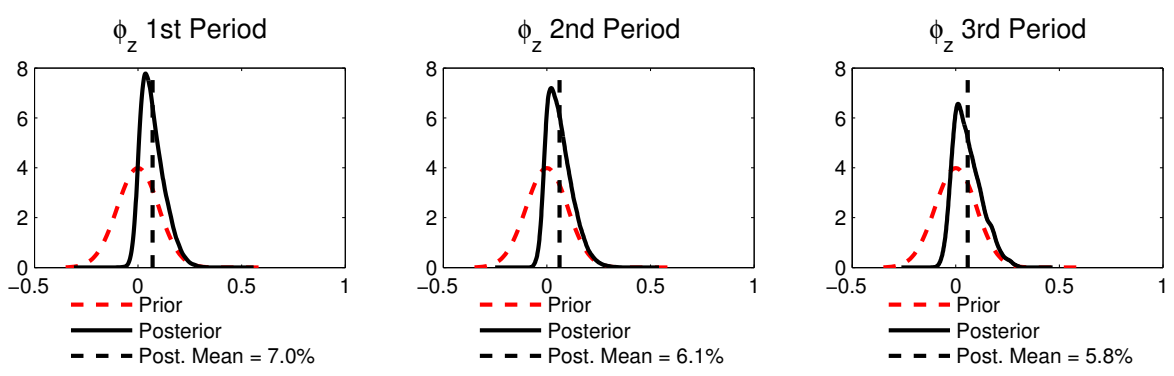

Figure 6.1: Prior and Posterior Distributions of $\phi_{z}$

In order to analyze how this phenomenon affects the predictions of the model, first, we impose the Fiscal regime, setting $\phi_{\pi}=\phi_{y}=\gamma_{g}=\gamma_{\tau}=0$. This implies that the nominal interest rate is constant and the fiscal policy does not respond to the debt level. Then, we set the rest of the parameters on the mean of their posteriors (for the period of 1955Q1-1966Q4 ${ }^{1}$ ) and compare the dynamic responses of some variables of interest to a monetary and fiscal policy shocks, under different values of $\phi_{z}$ and $\phi_{g}$ ("Indexation Parameters"). The table summarizing the estimation results is on the appendix (section C.5).

Figure 6.2 displays the impulse response functions (IRFs) of some variables of interest to a monetary policy shock that takes the form of positive realization of $\epsilon_{t}^{r}$ of size 0.25 . The red dashed lines represent the IRFs when the "Indexation Parameters"are set on their mean values and the black lines represents the IRFs when they are set to zero (perfect indexation).

When there is imperfect indexation the immediate inflation response to the shock is negative, whereas when indexation is perfect it is positive. This negative response in the short-run gets larger the less indexed is the fiscal instruments and the longer is the nominal debt maturity. The cumulative inflation response, measured by the price level response, is 0.20 percentage points higher when indexation is perfect. Moreover, when indexation is imperfect the debt level steady-state changes to a higher level (99\% higher than the initial level). This happens because the net transfers real value is permanently eroded by the higher inflation.

\footnotetext{
${ }^{1}$ The main points made here do not depend on the period choice.
} 

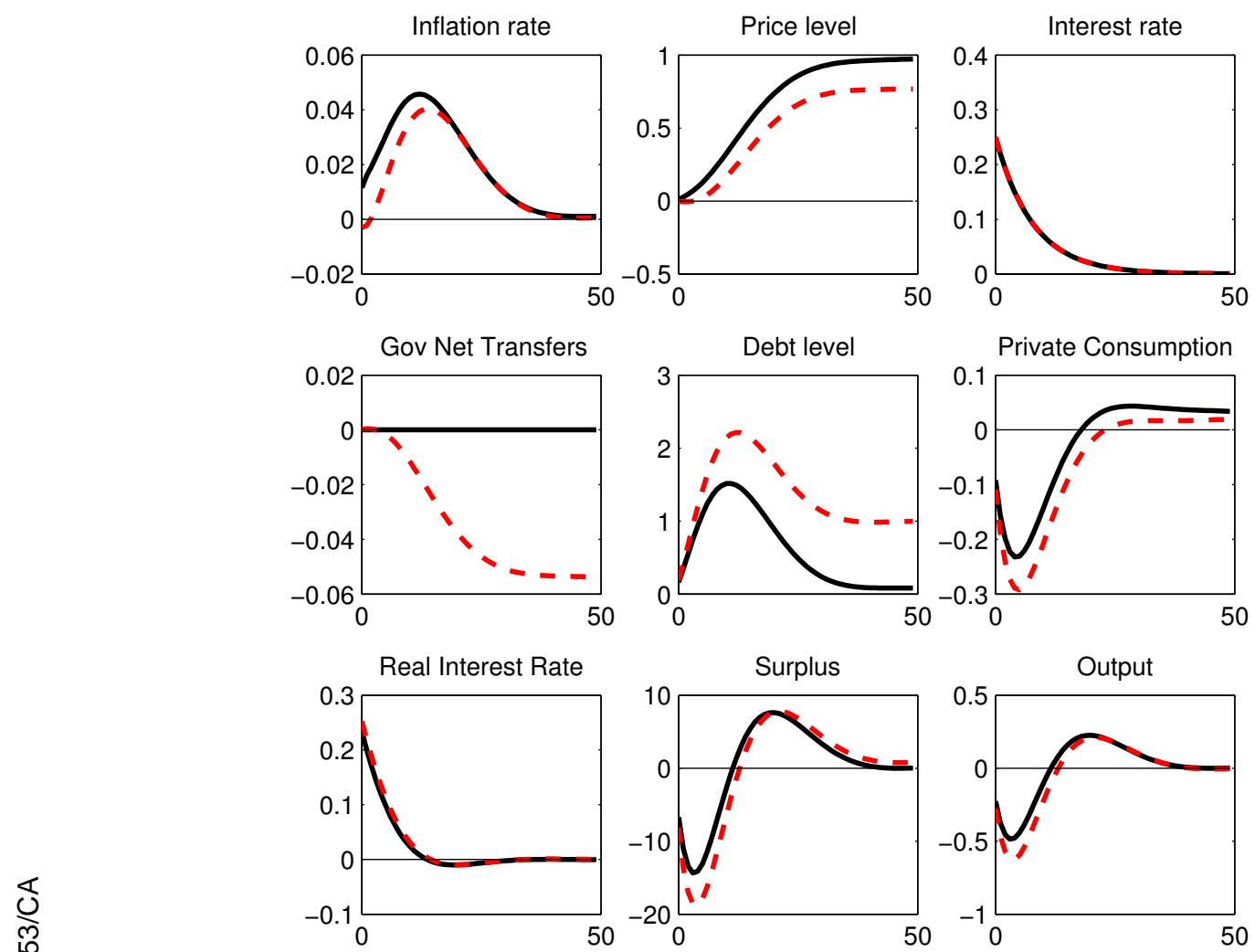

Figure 6.2: IRF Monetary Shock - Red (Dashed): $\phi_{z}=7.0 \%, \phi_{g}=1.7 \%$; Black: $\phi_{z}=\phi_{g}=0$

Figure 6.3 illustrates the IRFs of fiscal shock (an unexpected increase in net transfers). First, as expected, the inflationary result of the fiscal shock is lower when transfers are not totally indexed. As discussed in section 3, this happens because when part of the transfers are no indexed, inflation erodes not only the real value of debt but also the real value of transfers and purchases. Thus, less inflation is needed to reestablish the "fiscal intertemporal equilibrium condition". Second, when part of the transfers are not indexed, the inflation generated in the shock takes the real value of the transfers and purchases to a lower steady-state level. Consequently, debt and surpluses move to a higher steady-state level. This would not happen if the transfers were indexed to the past inflation. 

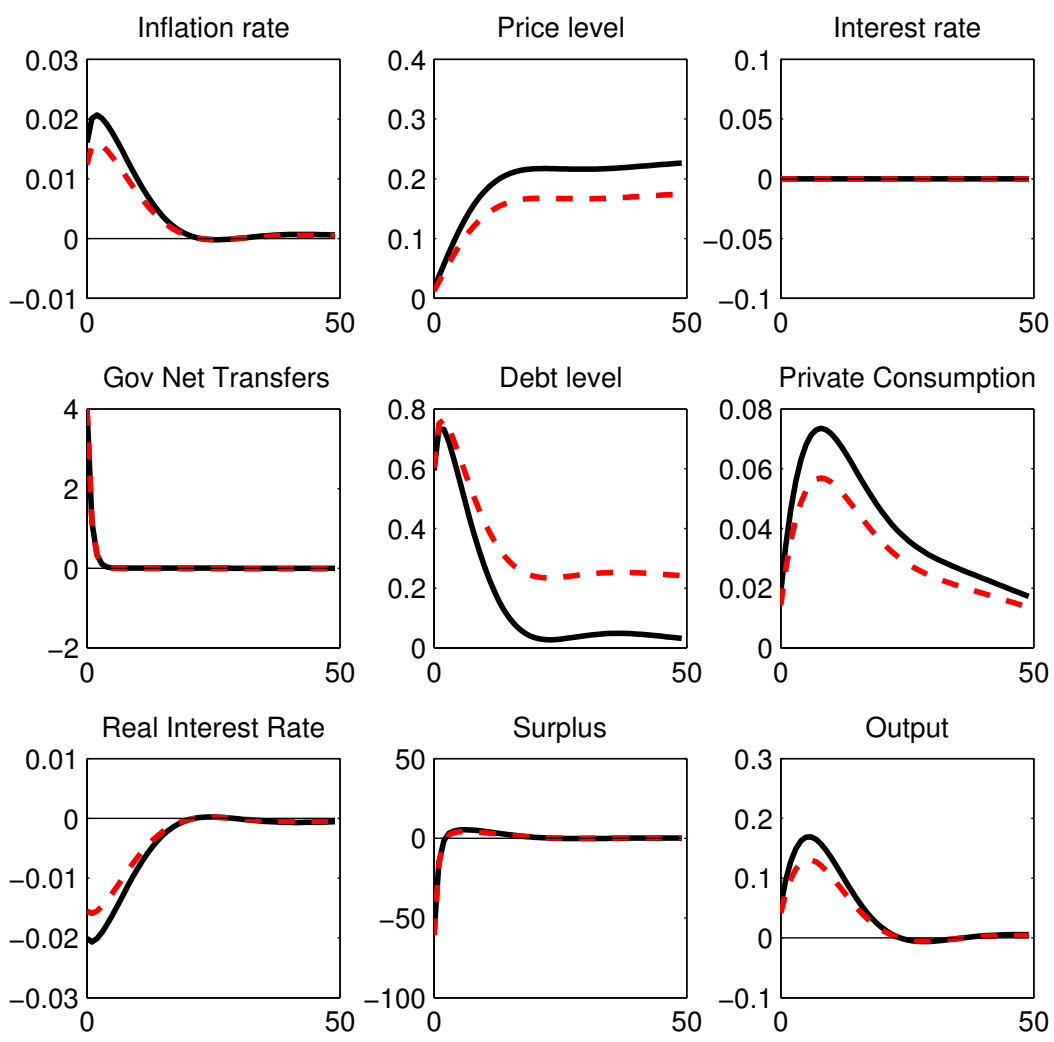

Figure 6.3: IRF Fiscal Shock - Red (Dashed): $\phi_{z}=7.0 \%, \phi_{g}=1.7 \%$; Black: $\phi_{z}=\phi_{g}=0$

\section{1 .2}

\section{The role of each channel}

In order to assess the role of each one of the channels operating in the FTPL, we compare the cumulative inflation following a negative fiscal shock, when different combinations of those channels are "available". Table 6.1 summarize the results.

To be available, each source of fiscal financing requires an specific condition on the model: for the debt to be used as a cushion, it must have some nominal part; the erosion of the real value of expenditures requires imperfect indexation; finally, for the real discount rate to respond to variations on government transfers, there must be some kind of nominal rigidity. The left side of the table indicates if these conditions are met (those market with " $\mathrm{X}$ ") and, therefore, if the related channels are operating. The right side indicates both the cumulative inflation and how much higher it is in relation to the benchmark (the case where all three are operating - the first line of the table). For instance, the value $17.70 \%$ represents the cumulative inflation in the case where all government debt is real, but there are still imperfect indexation 
$\left(\phi_{z}=7.0 \%, \phi_{g}=1.7 \%\right)$ and nominal stickiness (the parameters associated to these frictions are calibrated using the mean of their posteriors).

\begin{tabular}{c|c|c|c||c|c}
\hline & $\begin{array}{c}\text { Nominal } \\
\text { Debt }\end{array}$ & $\begin{array}{c}\text { Imperfect } \\
\text { Indexation }\end{array}$ & $\begin{array}{c}\text { Nominal } \\
\text { Rigidity }\end{array}$ & $\begin{array}{c}\text { Cumulative Inflation } \\
\text { (Price Level) }\end{array}$ & $\begin{array}{c}\text { Difference from the } \\
\text { Benchmark (bps) }\end{array}$ \\
\hline \hline 1 & $\mathrm{X}$ & $\mathrm{X}$ & $\mathrm{X}$ & $17.45 \%$ & 0 \\
2 & & $\mathrm{X}$ & $\mathrm{X}$ & $17.70 \%$ & 0.25 \\
3 & $\mathrm{X}$ & & $\mathrm{X}$ & $22.62 \%$ & 5.2 \\
4 & $\mathrm{X}$ & $\mathrm{X}$ & & $39.6 \%$ & 22.2 \\
5 & $\mathrm{X}$ & & & $87.04 \%$ & 69.6 \\
6 & & $\mathrm{X}$ & $\mathrm{X}$ & $72.49 \%$ & 55.0 \\
7 & & & \multicolumn{2}{|c}{ No equilibrium } \\
8 & & & \multicolumn{2}{|c}{5.6} \\
\hline
\end{tabular}

Table 6.1: Inflationary effect of a fiscal shock ("X"indicates the presence of a feature)

The first thing worth noting here is that, in an economy with nominal rigidity, the role of the nominal debt "cushion"is strikingly diminished. In a flexible-price economy with indexed surpluses, as in most FTPL literature ${ }^{2}$ the cumulative inflation response tend to infinity as the share of nominal debt goes to zero. However, when prices and nominal wages do not freely adjust, the change in that response is much lower. In fact, in our estimated model, when comparing the case where debt is totally nominal with the case where it is totally real, the cumulative inflation barely changes: it gets only 0.25 basis points higher, when surplus indexation is imperfect (lines 1 and 2 of Table 6.1), and 0.42 when surpluses are perfectly indexed (lines 3 and 7 ). This happens because in the sticky price model, the consumption is also affected by the fiscal shock, reducing the real interest rates and, therefore, the government real interest payments. From the fiscal perspective, the endogenous response of the real rates reduces the real interest expenditure and, hence, the"size" of the fiscal shock and its inflationary effect.

In the appendix (Section B) we show that this result also holds in a textbook New-Keynesian model with a moderate degree of price stickiness.

Figure 6.4 displays the IRFs of the model with and without nominal debt (both with nominal rigidities). It makes clear that is not only the inflation response that barely changes: the same applies to all other variables of interest. However, as we reduce the degree of nominal rigidity in the economy, the role of nominal debt as a source of fiscal financing increases. In a flex-price economy, comparing the case in which debt is nominal and surpluses are imperfectly indexed (line 4) with the case in which the only source of finance is the erosion

${ }^{2}$ As examples: (1), (2) and (6) 
of the real value of expenditures (line 6), we see that the inflation response is much higher (32.89 percentage points) in the latter.
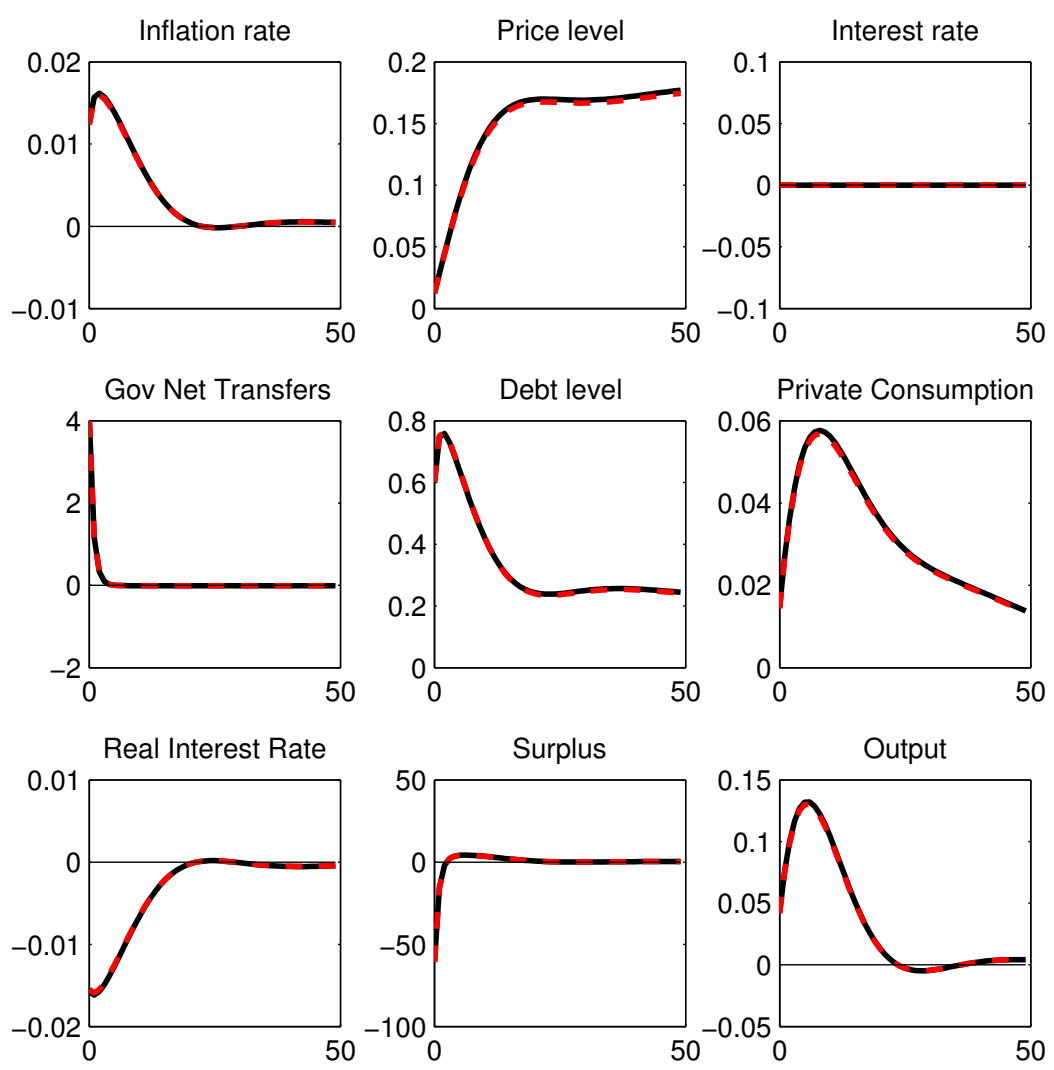

Figure 6.4: IRF Fiscal Shock - Black: All debt is real; Red (Dashed): All debt is nominal

A direct way of assessing the role of the "erosion of the real value of expenditures"as a source of fiscal financing is to compare the inflation response when this channel is available to the response when it is not. In the case where prices are rigid and the government has nominal debt, we compare lines 1 and 3. The difference of inflation attributed to this source is $(22.62 \%-17.45 \%)$ $5.17 \%$ percentage points. In the case where prices are rigid but debt is real, we compare lines 2 and 7 . In this case the difference of inflation attributed to this source is (23.04\%-17.7\%) $5.34 \%$ percentage points.

\section{2}

\section{Estimation Results (2nd Specification)}

In this specification the parameters of interest are $\theta_{z}$ and $\theta_{g}$ associated to the log-linearized equations for the real value of transfers and purchases: 


$$
\begin{aligned}
& \hat{z}_{t}=v_{z, t}+\eta_{t}^{z} \\
& v_{z, t}=\theta_{z}\left(v_{z, t-1}-\pi_{t}\right) \\
& \hat{g}_{t}=v_{g, t}-\gamma_{g} \hat{d}_{t-1}^{m}+\eta_{t}^{g} \\
& v_{g, t}=\theta_{g}\left(v_{g, t-1}-\pi_{t}\right)
\end{aligned}
$$

We assume as priors a beta distribution with mean 0.5 and standard deviation of 0.1 . Figures 6.5 and 6.6 depict the estimation results.
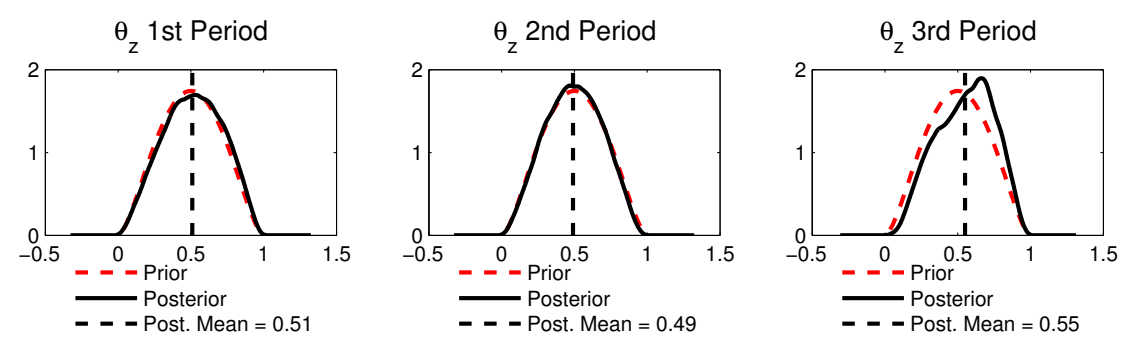

Figure 6.5: Prior and Posterior Distributions of $\theta_{z}$
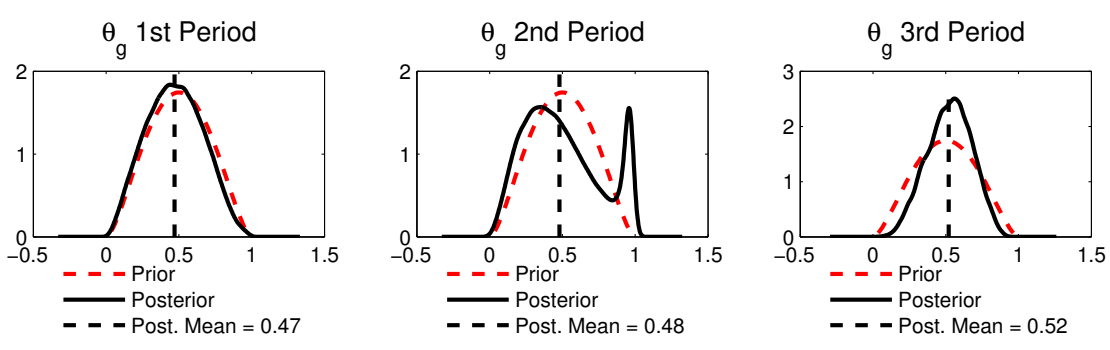

Figure 6.6: Prior and Posterior Distributions of $\theta_{g}$

Taken together, these estimates reveals that, in spite of being locally identified (under (28) methodology), data seems to add little information on their values, since the posterior estimates are almost identical to their prior distributions. In this case, there is little we can tell about their values and, therefore, on the counterfactuals exercises we use arbitrary values.

As in Section 6.1, where we analyzed the results under the first specification, here we set all the parameters, with exception of those related to monetary and fiscal policies, on the mean of their posteriors. Also, we choose different values of $\theta_{g}$ and $\theta_{z}$, to assess how would economy behave under different indexation structures. 
Figure 6.7 displays the impulse response functions (IRFs) of some variables of interest to a monetary policy shock that takes the form of positive realization of $\epsilon_{t}^{r}$ of size 0.25 . The red dashed lines and the blue dash-dotted lines represents the IRFs when the fiscal policy is imperfectly indexed, with parameters, respectively $\theta_{g}=\theta_{z}=0.75$ and $\theta_{g}=\theta_{z}=0.95$. The black lines represents the IRFs when they are set to zero (perfect indexation).

Qualitatively, the results are very similar to those found under the first specification: when surpluses are not perfectly indexed (i) inflation rates are lower, (ii) debt level grows more and (iii) output and private consumption have a larger variation. A relevant difference, however, is that, under this specification, variable such as the debt level, surpluses, government net transfers and private consumption do not move to a different steady-state after the shock. This happens because, now, the real value of purchases and transfers are eroded only temporarily, whereas under the first specification the effect is permanent. Furthermore, when that imperfection is more extreme (the case where $\theta_{z}=\theta_{g}=0.95$ ), the inflation response is negative in the short-run.
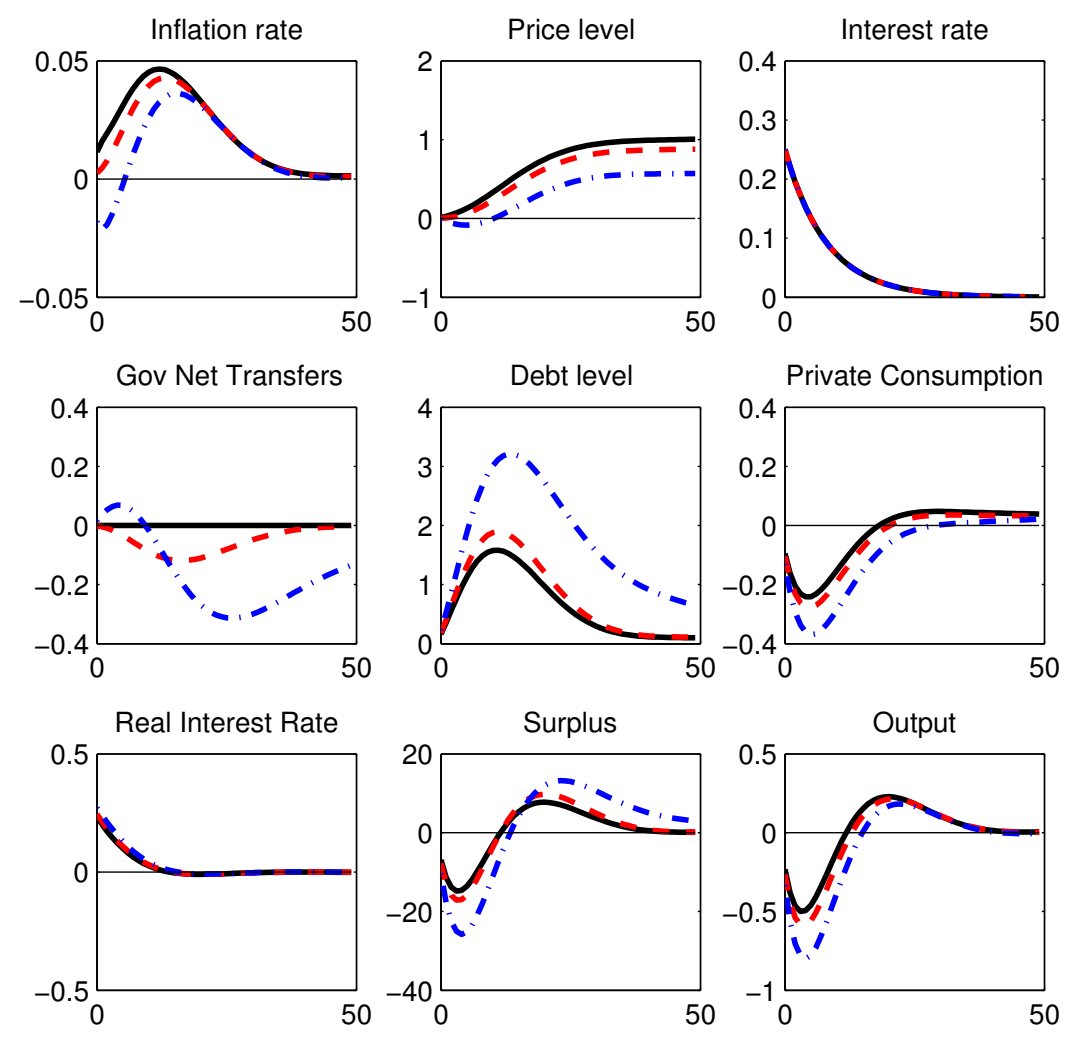

Figure 6.7: IRFs Monetary Shock - Blue (Dashed-dotted): $\theta_{z}=\theta_{g}=0.95$ Red (Dashed): $\theta_{z}=\theta_{g}=0.75$; Black: $\theta_{z}=\theta_{g}=0$ 
Figure 6.8 displays the IRFs to an expansionary fiscal shock that takes the form of positive realization of $\epsilon_{t}^{z}$ of size 4. Again, there are three different values for the indexation parameters: $0.95,0.75$ and zero. The results are also qualitatively similar to those under the first specifications, with the exception that here only the price level changes to a different steady-state. Also, when the fiscal variables have a very weak indexation $\left(\theta_{z}=\theta_{g}=0.95\right)$, the cumulative inflation response is reduced, virtually, to a half of what it would be under perfect indexation.
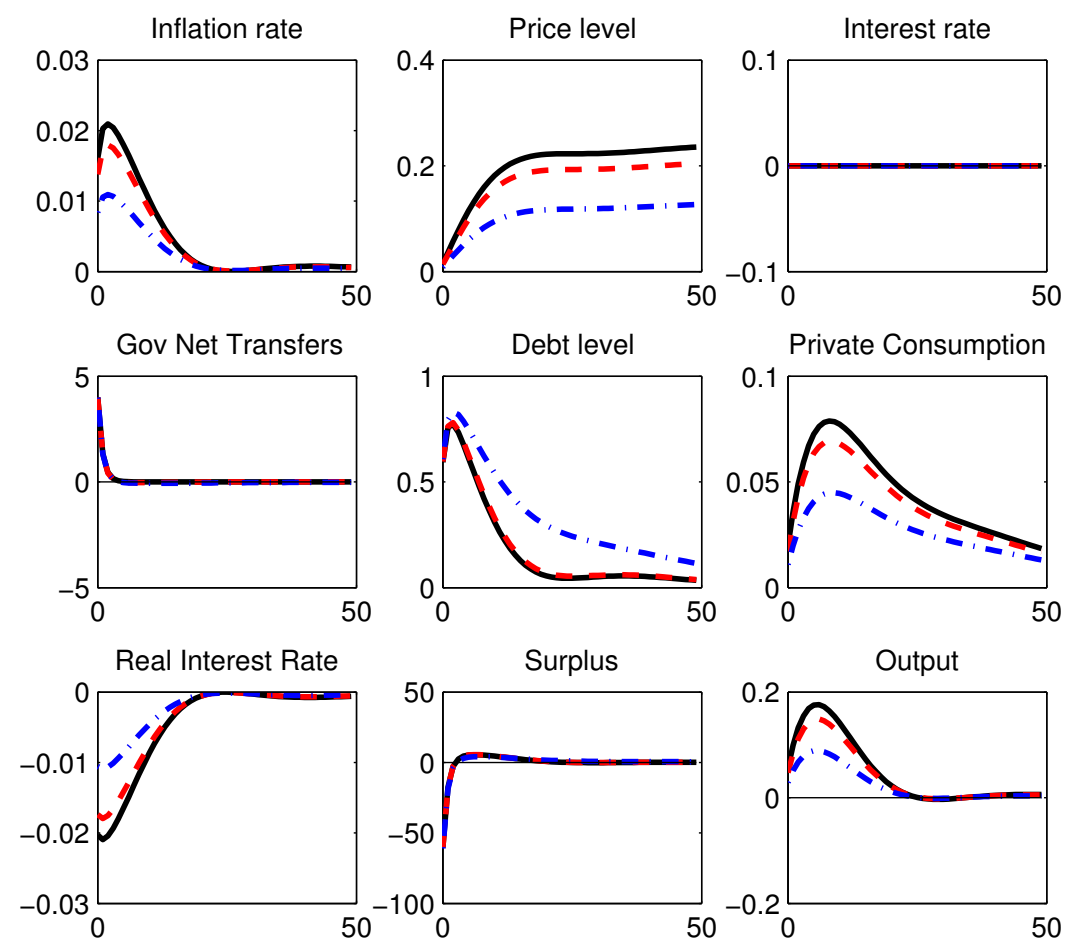

Figure 6.8: IRFs Fiscal Shock - Blue (Dashed-dotted): $\theta_{z}=\theta_{g}=0.95$ Red (Dashed): $\theta_{z}=\theta_{g}=0.75$; Black: $\theta_{z}=\theta_{g}=0$ 


\section{Conclusion}

In this article, we propose a model that accounts for different forms of indexation rules for the government purchases and transfers. We show that the FTPL may operate through the erosion of the real value of expenditures, other than the revaluation of the government debt. That implies theoretical changes on model dynamics. Through the estimation of the model, we evaluate the relevance of these changes for the U.S. economy. 


\section{References}

[1] LEEPER, E. M. Equilibria under 'active'and 'passive'monetary and fiscal policies. Journal of monetary Economics, v. 27, n. 1, p. 129-147, 1991.

[2] SIMS, C. A. A simple model for study of the determination of the price level and the interaction of monetary and fiscal policy. Economic theory, v. 4, n. 3, p. 381-399, 1994.

[3] DEL NEGRO, M.; SIMS, C. A. When does a central bank s balance sheet require fiscal support? Journal of Monetary Economics, v. 73, p. 1-19, 2015.

[4] BENIGNO, P.; WOODFORD, M. Optimal inflation targeting under alternative fiscal regimes. Technical report, National Bureau of Economic Research, 2006.

[5] WOODFORD, M. Fiscal requirements for price stability. Journal of Money, Credit \& Banking, v. 33, n. 3, p. 669-669, 2001.

[6] COCHRANE, J. H. Long-term debt and optimal policy in the fiscal theory of the price level. Econometrica, v. 69, n. 1, p. 69-116, 2001.

[7] TANZI, V. Inflation, lags in collection, and the real value of tax revenue. Staff Papers, v. 24, n. 1, p. 154-167, 1977.

[8] BACHA, E. O fisco e a inflação: uma interpretação do caso brasileiro. Revista de Economia política, v. 14, n. 1, p. 5-17, 1994.

[9] BACHA, E. Belíndia 2.0: fábulas e ensaios sobre o país dos contrastes. Editora José Olympio, 2015.

[10] BURNSIDE, A. C.; EICHENBAUM, M. S.; REBELO, S. On the fiscal implications of twin crises. In: Managing currency crises in emerging markets. University of Chicago Press, 2003. p. 187-224.

[11] SIMS, C. A. Paper money. The American Economic Review, v. 103, n. 2, p. 563-584, 2013.

[12] SIMS, C. A. Stepping on a rake: The role of fiscal policy in the inflation of the 1970s. European Economic Review, v. 55, n. 1, p. 48-56, 2011. 
[13] COCHRANE, J. H. Michelson-morley, occam and fisher: The radical implications of stable inflation at near-zero interest rates. 2016.

[14] LEEPER, E. M.; WALKER, T. B. Perceptions and misperceptions of fiscal inflation. Technical report, National Bureau of Economic Research, 2012.

[15] SARGENT, T. J.; WALLACE, N. Some unpleasant monetarist arithmetic. Federal reserve bank of minneapolis quarterly review, v. 5, n. 3, p. 1-17, 1981.

[16] LEEPER, E. M.; LEITH, C. Understanding inflation as a joint monetary-fiscal phenomenon. Handbook of Macroeconomics, v. 2, p. 2305-2415, 2016.

[17] COCHRANE, J. H. Monetary policy with interest on reserves. Journal of Economic Dynamics and Control, v. 49, p. 74-108, 2014.

[18] TRAUM, N.; YANG, S.-C. S. Monetary and fiscal policy interactions in the post-war us. European Economic Review, v. 55, n. 1, p. 140-164, 2011.

[19] CHRISTIANO, L. J.; EICHENBAUM, M.; EVANS, C. L. Nominal rigidities and the dynamic effects of a shock to monetary policy. Journal of political Economy, v. 113, n. 1, p. 1-45, 2005.

[20] SMETS, F.; WOUTERS, R. Shocks and frictions in us business cycles: A bayesian dsge approach. The American Economic Review, v. 97, n. 3, p. 586-606, 2007.

[21] LEEPER, E. M.; PLANTE, M.; TRAUM, N. Dynamics of fiscal financing in the united states. Journal of Econometrics, v. 156, n. 2, p. 304-321, 2010.

[22] DIXIT, A. K.; STIGLITZ, J. E. Monopolistic competition and optimum product diversity. The American Economic Review, v. 67, n. 3, p. 297-308, 1977.

[23] CALVO, G. A. Staggered prices in a utility-maximizing framework. Journal of monetary Economics, v. 12, n. 3, p. 383-398, 1983.

[24] GREENWOOD, J.; HERCOWITZ, Z.; KRUSELL, P. Long-run implications of investment-specific technological change. The American Economic Review, p. 342-362, 1997.

[25] DAVIG, T.; LEEPER, E. M. Monetary-fiscal policy interactions and fiscal stimulus. European Economic Review, v. 55, n. 2, p. 211-227, 2011.

[26] AN, S.; SCHORFHEIDE, F. Bayesian analysis of dsge models. Econometric reviews, v. 26, n. 2-4, p. 113-172, 2007. 
[27] FERNÁNDEZ-VILLAVERDE, J.; RAMÍREZ, J. F. R.; SCHORFHEIDE, F. Solution and estimation methods for dsge models. Technical report, National Bureau of Economic Research, 2016.

[28] ISKREV, N. Local identification in dsge models. Journal of Monetary Economics, v. 57, n. 2, p. 189-202, 2010. 
A

\section{Proof of the Proposition}

We log-linearize the equations of the model under the steady-state, organize it in a linear system and aply blanchard1980solution conditions. In the following equations $i_{t}=\ln \left(R_{t}\right) ; \rho=\ln \left(\beta^{-1}\right) . \pi_{t}$ and $b_{t}$ are, respectively, the log deviation of inflation and real debt from their steady-state.

Euler equation implies, for every period, that:

$$
R_{t}^{r}=\beta^{-1}
$$

Government flow budget constraint:

$$
b_{t}=\beta^{-1} b_{t-1}-\frac{1-\beta}{\beta} s_{t}
$$

Taylor rule:

$$
i_{t}=\rho+\phi_{\pi} \pi_{t}+\epsilon_{t}^{M}
$$

Fisher relation:

$$
i_{t}=\rho+E_{t} \pi_{t+1}
$$

Surplus:

$$
\frac{1-\beta}{\beta} s_{t}=\phi_{b} b_{t-1}+\phi_{p} p_{t}-\epsilon_{t}^{F}
$$

Where $\phi_{p}=\frac{(Z-T) / P}{b}$ measures the how relevant is the the nominal component of the surplus.

The log-linearized system of these equations can be represented as:

$$
E_{t}\left(\begin{array}{c}
b_{t} \\
\pi_{t+1} \\
p_{t}
\end{array}\right)=\left(\begin{array}{ccc}
\left(\frac{1}{\beta}-\phi_{b}\right) & -\phi_{p} & -\phi_{p} \\
0 & \phi_{\pi} & 0 \\
0 & 1 & 1
\end{array}\right)\left(\begin{array}{c}
b_{t-1} \\
\pi_{t} \\
p_{t-1}
\end{array}\right)+\left(\begin{array}{c}
\epsilon_{t}^{F} \\
\epsilon_{t}^{M} \\
0
\end{array}\right)
$$

The eigenvalues of the matrix are:

$$
\begin{aligned}
& \lambda_{1}=1 \\
& \lambda_{2}=\frac{1}{\beta}-\phi_{b} \\
& \lambda_{3}=\phi_{\pi}
\end{aligned}
$$

blanchard1980solution conditions for existence and uniqueness of a bounded solution are satisfied if:

$$
\left|\phi_{\pi}\right|>1 \text { and }\left|\frac{1}{\beta}-\phi_{b}\right|<1 \quad \text { (Monetary Regime) or }
$$


$\left|\phi_{\pi}\right|<1$ and $\left|\frac{1}{\beta}-\phi_{b}\right|>1 \quad$ (Fiscal Regime).

Note, finally, that the condition of $\phi_{p} \neq 0$ is also necessary, since if $\phi_{p}=0$ and $\left|\frac{1}{\beta}-\phi_{b}\right|>1$ the debt level has an explosive path, which violates the transversality condition.

$$
b_{t}=\left(\frac{1}{\beta}-\phi_{b}\right) b_{t-1}-\epsilon_{t}^{F} \Longrightarrow E_{t} b_{t+1}>b_{t}, \quad \forall t
$$

\section{A.1}

\section{Solution for the Price Level under Fiscal Regime}

The solution for the price level in the Fiscal Regime can be obtained through the government flow budget condition:

$$
b_{t}=\left(\frac{1}{\beta}-\phi_{b}\right) b_{t-1}-\phi_{p} p_{t}+\epsilon_{t}^{F}
$$

Defining $\left(\frac{1}{\beta}-\phi_{b}\right)^{-1} \equiv \gamma$ and $-\phi_{p} \equiv \phi$ :

$$
b_{t-1}=\gamma b_{t}+\gamma \phi p_{t}+\gamma \epsilon_{t}^{F}
$$

Taking expectations and substituting forward:

$$
b_{t-1}=\gamma \epsilon_{t}^{F}+\gamma \phi p_{t}+\gamma^{2} \phi E_{t} p_{t+1}+\gamma^{3} \phi E_{t} p_{t+2}+\ldots
$$

Now, from Taylor rule and Fisher relation:

$$
\mathbb{E}_{t}\left(p_{t+1}-p_{t}\right)=\phi_{\pi}\left(p_{t}-p_{t-1}\right)+\epsilon_{t}^{M}
$$

Which can be rewritten as a second order difference equation for the price level:

$$
\mathbb{E}_{t}\left(p_{t+1}\right)=\left(1+\phi_{\pi}\right) p_{t}-\phi_{\pi} p_{t-1}+\epsilon_{t}^{M}
$$

Rewriting in matrix form:

$$
\underbrace{\left[\begin{array}{c}
\mathbb{E}_{t} p_{t+1} \\
p_{t}
\end{array}\right]}_{E_{t} Z_{t+1}}=\underbrace{\left[\begin{array}{cc}
\left(1+\phi_{\pi}\right) & -\phi_{\pi} \\
1 & 0
\end{array}\right]}_{A} \underbrace{\left[\begin{array}{c}
p_{t} \\
p_{t-1}
\end{array}\right]}_{Z_{t}}+\underbrace{\left[\begin{array}{c}
\epsilon_{t}^{M} \\
0
\end{array}\right]}_{V_{t}}
$$

So we have:

$$
b_{t-1}=\gamma \epsilon_{t}^{F}+\phi \gamma\left[\begin{array}{ll}
1 & 0
\end{array}\right] Z_{t}+\gamma E_{t}\left[\left[\begin{array}{ll}
1 & 0
\end{array}\right] \phi \gamma Z_{t+1}+\gamma b_{t+1}\right]
$$


if $\left|\phi_{\pi} \gamma\right|<1$, then both eigenvalues of $(\gamma A)$ are, in absolute value, lower than 1. So:

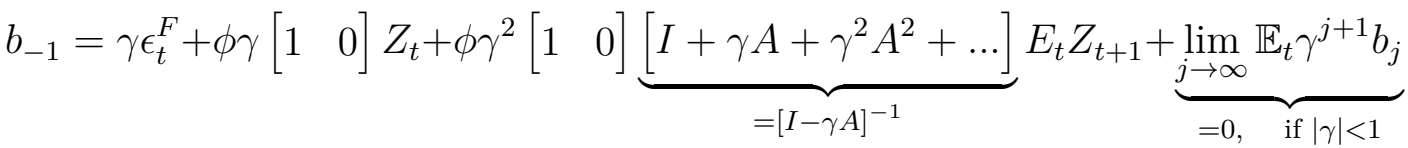

$$
\begin{aligned}
& {\left[I-\gamma\left[\begin{array}{cc}
\left(1+\phi_{\pi}\right) & -\phi_{\pi} \\
1 & 0
\end{array}\right]\right]^{-1} \equiv B} \\
& b_{-1}=\gamma \epsilon_{t}^{F}+\phi \gamma\left[\begin{array}{ll}
1 & 0
\end{array}\right] Z_{t}+\phi \gamma^{2}\left[\begin{array}{ll}
1 & 0
\end{array}\right] B E_{t} Z_{t+1}
\end{aligned}
$$

Assuming $p_{-1}=0$ :

$p_{t}=b_{t-1} \frac{(1-\gamma)\left(1-\phi_{\pi} \gamma\right)}{\phi \gamma\left[(1-\gamma)\left(1-\gamma \phi_{\pi}\right)+\gamma\right]}-\epsilon_{t}^{M} \frac{\gamma}{\phi \gamma\left[(1-\gamma)\left(1-\gamma \phi_{\pi}\right)+\gamma\right]}-\epsilon_{t}^{F} \frac{(1-\gamma)\left(1-\phi_{\pi} \gamma\right)}{\phi\left[(1-\gamma)\left(1-\gamma \phi_{\pi}\right)+\gamma\right]}$

Note that, the condition $|\gamma|<1$ is equivalent to $\left|\frac{1}{\beta}-\phi_{b}\right|>1$.

\section{A.2}

\section{Calibration}

The calibration used to generate the IRFs of a monetary policy shock (displayed in Figure ??) is shown on table below. The parameter $\phi_{p}=\frac{(Z-T) / P}{b}$ is equal to $\frac{(Z-T) / P}{s} \frac{s}{b}=\frac{(Z-T) / P}{s} \frac{(1-\beta)}{\beta}$. So assuming that $T=0$ (all revenue is indexed), $\frac{z+Z / P}{s}=4$ (transfers are 4 times higher than surpluses) and that $20 \%$ of the transfers are not indexed, than $\phi_{p}=0.008$.

\begin{tabular}{ll} 
Parameter & Value \\
\hline$\beta$ & 0.99 \\
$\sigma$ & 1 \\
$\phi_{\pi}$ & 0 \\
$\phi_{b}$ & 0 \\
$\phi_{p}$ & 0.008
\end{tabular}

Table A.1: Calibration - Frictionless, Endowment Economy Model 
B

\section{FTPL in a textbook New-Keynesian Model - Nominal vs Real debt}

We simulate an standard New-Keynesian model described in gali2015monetary, including a simple fiscal policy rule for surpluses. The log-linearized equations are:

$$
\begin{aligned}
& \pi_{t}=\beta E_{t} \pi_{t+1}+\kappa y_{t} \\
& y_{t}=E_{t} y_{t+1}-\sigma^{-1} r_{t} \\
& i_{t}=\phi_{\pi} \pi_{t}+\eta_{t}^{m} \\
& r_{t}=i_{t}-E_{t} \pi_{t+1} \\
& b_{t-1}-(1-\lambda) \pi_{t}=(1-\beta) s_{t}+\beta\left[\lambda\left(b_{t}-r_{t}\right)+(1-\lambda)\left(b_{t}-i_{t}\right)\right] \\
& s_{t}=\gamma b_{t-1}-(z / s) z_{t} \\
& z_{t}=\eta_{t}^{z} \\
& \eta_{t}^{z}=\rho \eta_{t-1}^{z}+\epsilon_{t}^{z}
\end{aligned}
$$

The calibration is:

\begin{tabular}{cc} 
Parameter & Value \\
\hline$\beta$ & 0.99 \\
$\sigma$ & 1 \\
$\alpha$ & $1 / 3$ \\
$\theta$ & $2 / 3$ \\
$\phi$ & 1 \\
$\epsilon$ & 6 \\
$\phi_{\pi}$ & 0 \\
$\gamma$ & 0 \\
$\rho$ & 0.5 \\
$\lambda$ & $\{0,1\}$ \\
$(\mathrm{z} / \mathrm{s})$ & 4
\end{tabular}

Table B.1: Calibration NK Model

As in gali2015monetary, the parameter $\kappa \equiv \lambda_{2}(\sigma+((\phi+\alpha) /(1-\alpha)))$, where $\lambda_{2} \equiv(((1-\theta)(1-\beta * \theta)) / \theta)((1-\alpha) /(1-\alpha+\alpha \epsilon))$. 
Appendix B. FTPL in a textbook New-Keynesian Model-Nominal vs Real debta
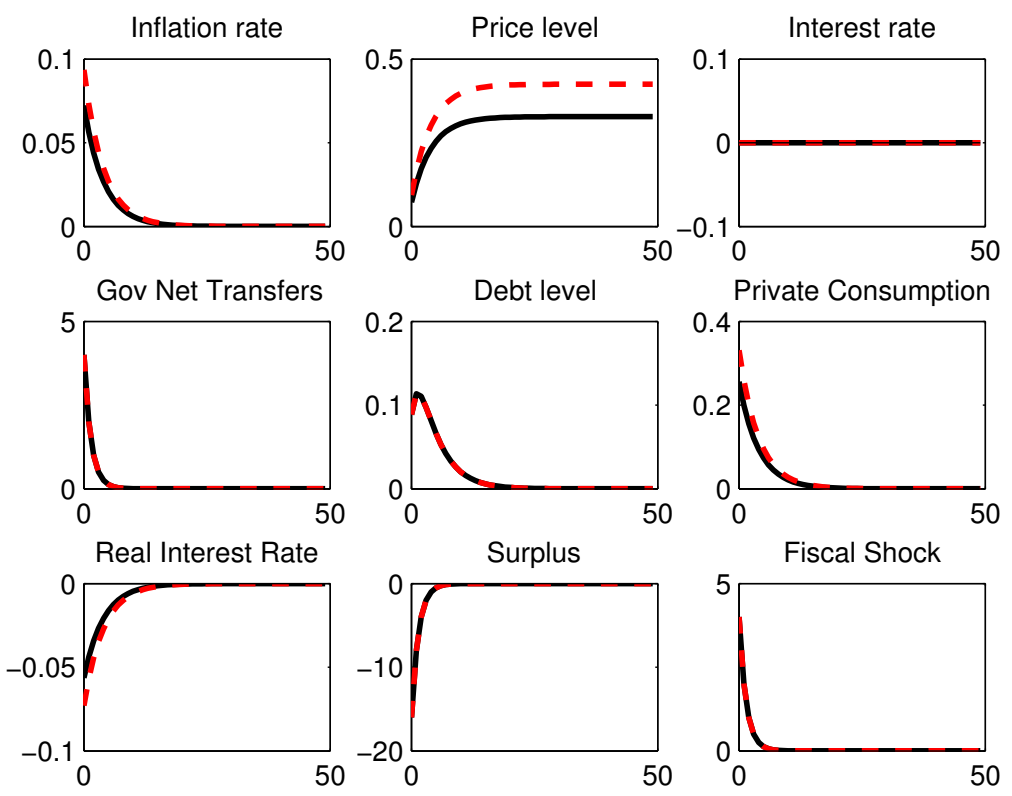

Figure B.1: IRF Fiscal Shock - Red (Dashed): $\lambda=1$ (Real debt); Black: $\lambda=0$ (Nominal debt)
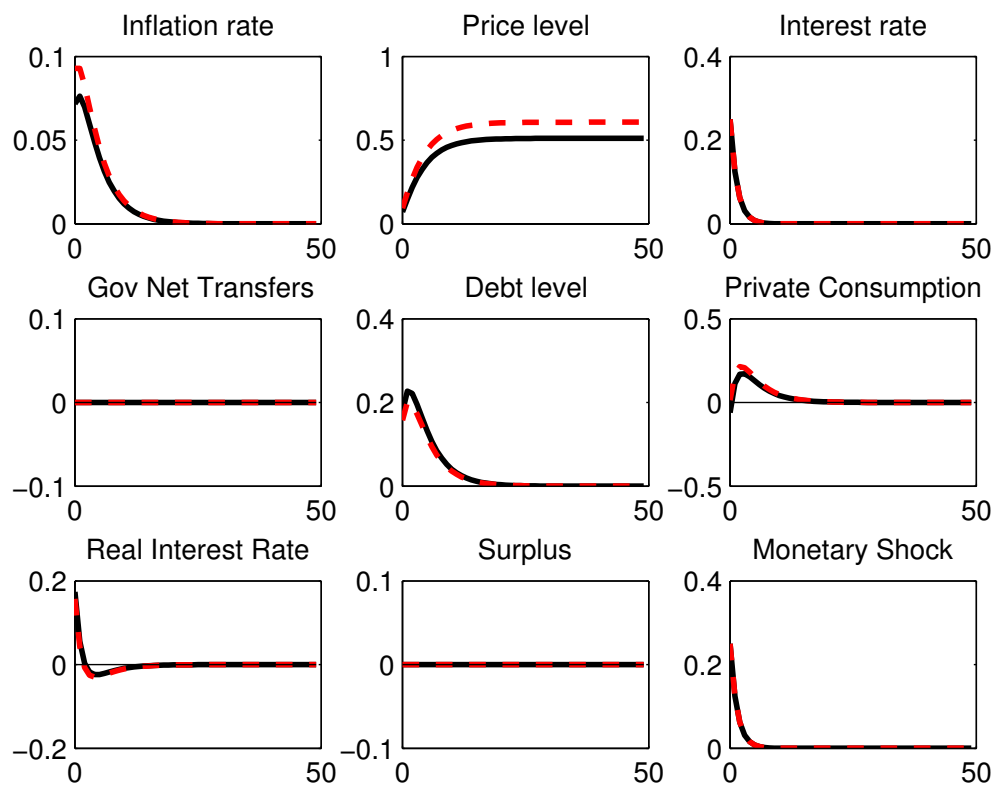

Figure B.2: IRF Monetary Shock - Red (Dashed): $\lambda=1$ (Real debt); Black: $\lambda=0$ (Nominal debt) 
C

\section{Model Equations, Data Description and Results}

\section{C.1}

\section{Model Equations (Log-Linearized)}

Here we present all the equations used to simulate the model:

Production function:

$$
\hat{y}_{t}=\alpha \hat{k}_{t}+(1-\alpha) \hat{L}_{t}
$$

Capital-Labor ratio:

$$
\hat{R}_{t}^{k}-\hat{w}_{t}=\hat{L}_{t}-\hat{k}_{t}
$$

Marginal Cost:

$$
\hat{m} c_{t}=\alpha \hat{R}_{t}^{k}+(1-\alpha) \hat{w}_{t}
$$

Household FOC for consumption:

$$
\hat{\lambda}_{t}=\hat{R}_{t}+E_{t}\left[\hat{\lambda}_{t+1}\right]-E_{t}\left[\hat{\pi}_{t+1}\right]-E_{t}\left[\hat{a}_{t+1}\right]
$$

Euler Equation:

$$
\hat{\lambda}_{t}=\hat{R}_{t}+E_{t}\left[\hat{\lambda}_{t+1}\right]-E_{t}\left[\hat{\pi}_{t+1}\right]-E_{t}\left[\hat{a}_{t+1}\right]
$$

Household FOC for capacity utilization:

$$
\hat{R}_{t}^{k}-\frac{\tau}{1-\tau} \hat{\tau}_{t}=\frac{\psi}{1-\psi} \hat{\nu}_{t}
$$

Household FOC for capital:

$$
\hat{q}_{t}=E_{t} \hat{\lambda}_{t+1}-\hat{\lambda}_{t}-E_{t} \hat{a}_{t+1}+\beta e^{-\gamma}(1-\tau) R^{k} E_{t} \hat{R}_{t+1}^{k}-\beta e^{-\gamma} \tau R^{k} E_{t} \hat{\tau}_{t+1}+\beta e^{-\gamma}(1-\delta) q E_{t} \hat{q}_{t+1}
$$

Household FOC for investment:

$$
(1+\beta) \hat{i}_{t}-\frac{1}{s e^{2 \gamma}} \hat{q}_{t}+\hat{a}_{t}-E_{t} \hat{i}_{t+1}-E_{t} \hat{a}_{t+1}=\hat{i}_{t-1}
$$

Effective capital:

$$
\hat{k}_{t}=\hat{\nu}_{t}+\hat{\bar{k}}_{t-1}-\hat{a}_{t}
$$


Law of motion for capital:

$$
\hat{\bar{k}}_{t}=(1-\delta) e^{-\gamma}\left(\hat{\bar{k}}_{t-1}-\hat{a}_{t}\right)+\left[1-(1-\delta) e^{-\gamma}\right]\left(\hat{u}_{t}^{i}+\hat{i}_{t}\right)
$$

Phillips curve:

$$
\pi_{t}=\frac{\left(1-\beta \omega^{p}\right)\left(1-\omega^{p}\right)}{\omega^{p}\left(1+\beta \chi_{p}\right)} \hat{m} c_{t}+\frac{\chi_{p}}{1+\beta \chi_{p}} \pi_{t-1}+\frac{\beta}{1+\beta \chi_{p}} E_{t}\left\{\pi_{t+1}\right\}+\hat{\eta}_{t}^{*}
$$

Where $\hat{\eta}_{t}^{*}=\frac{\left(1-\beta \omega^{p}\right)\left(1-\omega^{p}\right)}{\omega^{p}\left(1+\beta \chi_{p}\right)} \hat{\eta}_{t}$ is the rescaled shock.

Aggregate resource constraint:

$$
\hat{y}_{t}=(c / y) \hat{c}_{t}+(i / y) \hat{i}_{t}+(g / y) \hat{g}_{t}+\psi^{\prime}(1)(k / y) \hat{\nu}_{t}
$$

Government budget constraint:

$$
\hat{b}_{t-1}^{m}-(1-\lambda) \hat{\pi}_{t}-a_{t}=(1-\beta) \hat{s}_{t}+\beta\left\{\lambda\left[\hat{b}_{t}^{m}-\hat{r}_{t}\right]+(1-\lambda)\left[\hat{b}_{t}^{m}+(1-\rho) \hat{P}_{t}^{m}\right]\right\}
$$

Where $\lambda=\frac{b^{r}}{b^{r}+\frac{\left(1+\rho P^{m}\right) B^{m}}{P}}$ is the fraction of the real debt in the total debt. Note

also that $\frac{s}{b^{r}+\frac{\left(1+\rho P^{m}\right) B^{m}}{P}}=(1-\beta)$ is the quotient between the real surplus and the real value of ${ }^{P}$ debt.

Long-term bond portfolio price:

$$
\hat{P}_{t}^{m}=\beta_{t} \hat{P}_{t+1}^{m}-\hat{R}_{t}
$$

Government surplus:

$$
\hat{s}_{t}=(T / s) \hat{T}_{t}-(g / s) \hat{g}_{t}-(z / s) \hat{z}_{t}
$$

Transfers rule (1st specification):

$$
\hat{z}_{t}=-\underbrace{\left(\frac{V_{2} / P}{z}\right)}_{\phi_{z}} \hat{p}_{t}+\eta_{t}^{z}
$$

Transfers rule (2nd specification):

$$
\begin{aligned}
& \hat{z}_{t}=v_{z, t}+\eta_{t}^{z} \\
& v_{z, t}=\theta_{z}\left(v_{z, t-1}-\pi_{t}\right)
\end{aligned}
$$

Government purchases rule (1st specification):

$$
\hat{g}_{t}=-\gamma_{g} \hat{d}_{t-1}^{m}-\underbrace{\left(\frac{G_{2} / P}{z}\right)}_{\phi_{g}} \hat{p}_{t}+\eta_{t}^{g}
$$


Government purchases rule (2nd specification):

$$
\begin{aligned}
& \hat{g}_{t}=v_{g, t}-\gamma_{g} \hat{d}_{t-1}^{m}+\eta_{t}^{g} \\
& v_{g, t}=\theta_{g}\left(v_{g, t-1}-\pi_{t}\right)
\end{aligned}
$$

Tax-rate rule:

$$
\tau_{t}=\rho_{\tau} \tau_{t-1}+\left(1-\rho_{\tau}\right) \gamma_{\tau} \hat{d}_{t-1}^{m}+\epsilon_{t}^{\tau}, \epsilon_{t}^{\tau} \sim N\left(0, \sigma^{\tau}\right)
$$

Monetary-policy rule:

$$
\hat{R}_{t}=\rho_{r} \hat{R}_{t-1}+\left(1-\rho_{r}\right)\left(\phi_{\pi} \hat{\pi}_{t}+\phi_{y} \hat{Y}_{t}\right)+\epsilon_{t}^{r}, \quad \epsilon_{t}^{r} \sim N\left(0, \sigma^{r}\right)
$$

\section{C.2}

\section{Equation for the government budget constraint}

Government Budget Constraint:

$$
b_{t-1}^{r}+\frac{B_{t-1}^{m}\left(1+\rho P_{t}^{m}\right)}{P_{t-1}} \frac{P_{t-1}}{P_{t}}=s_{t}+Q_{t}^{r} b_{t}^{r}+\frac{B_{t}^{m} P_{t}^{m}}{P_{t}}
$$

Defining $\tilde{x}_{t} \equiv X_{t} / A_{t}$ and, specifically $\tilde{b}_{t}^{m} \equiv \frac{B_{t}^{m}}{A_{t} P_{t}}$ :

$$
\tilde{b}_{t-1}^{r} \frac{A_{t-1}}{A_{t}}+\tilde{b}_{t-1}^{m}\left(1+\rho P_{t}^{m}\right) \frac{P_{t-1}}{P_{t}} \frac{A_{t-1}}{A_{t}}=\tilde{s}_{t}+Q_{t}^{r} \tilde{b}_{t}^{r}+\tilde{b}_{t-1}^{m} P_{t}^{m}
$$

Log-Linearized:

$$
\hat{b}_{t-1}^{m}-(1-\lambda) \hat{\pi}_{t}-a_{t}=(1-\beta) \hat{s}_{t}+\beta\left\{\lambda\left[\hat{b}_{t}^{m}-\hat{r}_{t}\right]+(1-\lambda)\left[\hat{b}_{t}^{m}+(1-\rho) \hat{P}_{t}^{m}\right]\right\}
$$

Where $\lambda=\frac{b^{r}}{b^{r}+\frac{\left(1+\rho P^{m}\right) B^{m}}{P}}$ is the fraction of the real debt in the total debt. Note also that $\frac{s}{b^{r}+\frac{\left(1+\rho P^{m}\right) B^{m}}{P}}=(1-\beta)$ is the quotient between the real surplus and the real value of debt.

\section{C.3}

\section{Data Description}

As noted in the text, we use exactly the same date as traum2011monetary, with the same transformations All the data used in the estimation is from the National Income and Product Accounts Tables, by the Bureau of Economic Analysis. All data in levels are nominal values. Nominal 
data are converted to real values by the price deflator for GDP (Table 1.1.4, line 1).

\section{Consumption}

Consumption, $C$, is defined as the sum of personal consumption expenditures on nondurable goods (Table 1.1.5, line 5) and services (Table 1.1.5, line 6).

\section{Investment}

Investment, $I$, is defined as the sum of personal consumption expenditures on durable goods (Table 1.1.5, line 4) and gross private domestic investment (Table 1.1.5, line 7).

\section{Tax revenue}

Tax revenue, $T$, is defined as the sum of federal personal current tax (Table 3.2, line 3), federal taxes on corporate income (Table 3.2, line 7), and federal contributions for social insurance (Table 3.2, line 11).

\section{Government spending}

Government spending, G, is defined as federal government consumption expenditure and investment (Table 1.1.5, line 22).

\section{Government debt}

Government debt, B, is the market value of privately held gross federal debt, published by the Federal Reserve Bank of Dallas. The quarterly data are the monthly data at the beginning of each quarter.

\section{Hours worked}

Hours worked are constructed from the following variables:

$H$ : the index for nonfarm business, all persons, average weekly hours duration, $1992=100$, seasonally adjusted (from the Department of Labor).

Emp: civilian employment for 16 years and over, measured in thousands, seasonally adjusted (from the Department of Labor, Bureau of Labor Statistics, CE16OV). The series is transformed into an index where 1992Q3=100. Hours worked are then defined as

$$
N=\frac{H^{*} E m p}{100}
$$

\section{Wage rate}

The wage rate is defined as the index for hourly compensation for nonfarm business, all persons, $1992=100$, seasonally adjusted (from the U.S. Department of Labor).

\section{Inflation}

The gross inflation rate is defined using the price deflator for GDP (Table 1.1.4, line 1).

\section{Interest rate}


The nominal interest rate is defined as the average of daily figures of the federal funds rate (from the Board of Governors of the Federal Reserve System).

\section{4}

\section{Definition of observables}

The observable variable $\mathrm{X}$ is defined by making the following transformation to variable $\mathrm{x}$ :

$$
X=\ln \left(\frac{x}{\text { Popindex }}\right) * 100
$$

where Popindex is the index of Pop, constructed such that 1992Q3 = 1; Pop the civilian noninstitutional population in thousands, ages 16 years and over, seasonally adjusted (from the Bureau of Labor Statistics), LNS10000000; $\mathrm{x}=$ consumption, investment, hours worked, government spending, tax revenues. The real wage rate is defined in the same way, except that it is not divided by the total population.

C.5

\section{Estimation Results}

\begin{tabular}{|c|c|c|c|c|c|c|c|c|c|c|c|c|}
\hline \multirow[b]{2}{*}{ Parameters } & \multirow[b]{2}{*}{ Prior Mean } & \multirow[b]{2}{*}{ Prior Dist } & \multirow[b]{2}{*}{ Prior Stdv } & \multicolumn{3}{|c|}{ 1955Q1-1966Q4 } & \multicolumn{3}{|c|}{ 1967Q1-1979Q2 } & \multicolumn{3}{|c|}{ 1984Q1-2007Q4 } \\
\hline & & & & Post. Mean & 0.05 & 0.95 & Post. Mean & 0.05 & 0.95 & Post. Mean & 0.05 & 0.95 \\
\hline$\gamma$ & 0.005 & norm & 0.0005 & 0.005 & 0.004 & 0.006 & 0.005 & 0.004 & 0.006 & 0.005 & 0.005 & 0.006 \\
\hline$\nu$ & 2 & gamma & 0.75 & 2.59 & 1.26 & 3.86 & 2.22 & 1.03 & 3.37 & 2.85 & 1.50 & 4.23 \\
\hline$\theta$ & 0.5 & norm & 0.2 & 0.92 & 0.89 & 0.97 & 0.94 & 0.90 & 0.98 & 0.85 & 0.80 & 0.90 \\
\hline$\psi$ & 0.5 & norm & 0.2 & 0.33 & 0.03 & 0.59 & 0.32 & 0.09 & 0.55 & 0.43 & 0.22 & 0.64 \\
\hline $\mathrm{s}$ & 4 & gamma & 1 & 3.83 & 2.40 & 5.21 & 4.23 & 2.71 & 5.68 & 5.50 & 3.93 & 7.05 \\
\hline$\omega_{p}$ & 0.66 & beta & 0.1 & 0.87 & 0.79 & 0.94 & 0.70 & 0.63 & 0.77 & 0.94 & 0.91 & 0.98 \\
\hline$\omega_{w}$ & 0.66 & beta & 0.1 & 0.73 & 0.63 & 0.82 & 0.73 & 0.64 & 0.82 & 0.86 & 0.80 & 0.92 \\
\hline$\chi_{p}$ & 0.5 & beta & 0.152 & 0.27 & 0.08 & 0.45 & 0.45 & 0.26 & 0.64 & 0.26 & 0.07 & 0.45 \\
\hline$\chi_{w}$ & 0.5 & beta & 0.152 & 0.46 & 0.24 & 0.69 & 0.55 & 0.33 & 0.78 & 0.39 & 0.17 & 0.60 \\
\hline$\phi_{\pi}$ & 1.5 & norm & 0.25 & 1.72 & 1.37 & 2.09 & 1.63 & 1.28 & 2.00 & 1.89 & 1.52 & 2.30 \\
\hline$\phi_{y}$ & 0.125 & norm & 0.05 & 0.14 & 0.06 & 0.22 & 0.16 & 0.09 & 0.23 & 0.14 & 0.08 & 0.21 \\
\hline$\gamma_{g}$ & 0.05 & norm & 0.05 & 0.02 & -0.03 & 0.07 & 0.00 & -0.03 & 0.04 & -0.01 & -0.03 & 0.02 \\
\hline$\gamma_{\tau}$ & 0.15 & norm & 0.05 & 0.12 & 0.05 & 0.19 & 0.11 & 0.05 & 0.18 & 0.05 & 0.04 & 0.06 \\
\hline$\phi_{g}$ & 0 & norm & 0.1 & 0.02 & -0.14 & 0.17 & 0.10 & -0.05 & 0.25 & 0.07 & -0.09 & 0.22 \\
\hline$\phi_{z}$ & 0 & norm & 0.1 & 0.07 & -0.02 & 0.16 & 0.06 & -0.03 & 0.16 & 0.06 & -0.04 & 0.17 \\
\hline$\rho_{a}$ & 0.7 & beta & 0.2 & 0.54 & 0.38 & 0.70 & 0.37 & 0.19 & 0.54 & 0.48 & 0.36 & 0.61 \\
\hline$\rho_{b}$ & 0.7 & beta & 0.2 & 0.33 & 0.11 & 0.54 & 0.41 & 0.19 & 0.63 & 0.93 & 0.87 & 0.98 \\
\hline$\rho_{r}$ & 0.7 & beta & 0.2 & 0.88 & 0.85 & 0.92 & 0.91 & 0.87 & 0.95 & 0.87 & 0.84 & 0.90 \\
\hline$\rho_{i}$ & 0.7 & beta & 0.2 & 0.67 & 0.45 & 0.90 & 0.65 & 0.34 & 0.95 & 0.87 & 0.77 & 0.96 \\
\hline$\rho_{p}$ & 0.7 & beta & 0.2 & 0.70 & 0.48 & 0.92 & 0.28 & 0.08 & 0.46 & 0.54 & 0.26 & 0.79 \\
\hline$\rho_{w}$ & 0.7 & beta & 0.2 & 0.40 & 0.17 & 0.63 & 0.43 & 0.16 & 0.70 & 0.26 & 0.11 & 0.41 \\
\hline$\rho_{g}$ & 0.7 & beta & 0.2 & 0.95 & 0.88 & 1.00 & 0.99 & 0.97 & 1.00 & 0.99 & 0.99 & 1.00 \\
\hline$\rho_{t}$ & 0.7 & beta & 0.2 & 0.96 & 0.94 & 0.99 & 0.88 & 0.75 & 0.99 & 0.90 & 0.83 & 0.97 \\
\hline$\rho_{z}$ & 0.7 & beta & 0.2 & 0.29 & 0.10 & 0.47 & 0.43 & 0.24 & 0.62 & 0.29 & 0.13 & 0.43 \\
\hline$\sigma_{a}$ & 0.1 & invg & 2 & 1.14 & 0.94 & 1.33 & 0.97 & 0.81 & 1.13 & 0.77 & 0.68 & 0.87 \\
\hline$\sigma_{g}$ & 0.1 & invg & 2 & 2.24 & 1.86 & 2.61 & 2.00 & 1.66 & 2.34 & 1.64 & 1.44 & 1.84 \\
\hline$\sigma_{m}^{9}$ & 0.1 & invg & 2 & 0.22 & 0.18 & 0.26 & 0.18 & 0.14 & 0.21 & 0.14 & 0.12 & 0.15 \\
\hline$\sigma_{i}$ & 0.1 & invg & 2 & 1.03 & 0.69 & 1.36 & 1.03 & 0.69 & 1.39 & 0.34 & 0.26 & 0.41 \\
\hline$\sigma_{b}$ & 0.1 & invg & 2 & 5.50 & 1.19 & 9.41 & 5.88 & 1.30 & 10.30 & 0.31 & 0.10 & 0.52 \\
\hline$\sigma_{p}$ & 0.1 & invg & 2 & 0.08 & 0.04 & 0.11 & 0.20 & 0.15 & 0.25 & 0.08 & 0.05 & 0.11 \\
\hline$\sigma_{w}$ & 0.1 & invg & 2 & 0.14 & 0.10 & 0.19 & 0.19 & 0.12 & 0.26 & 0.25 & 0.20 & 0.31 \\
\hline$\sigma_{t}$ & 0.1 & invg & 2 & 2.43 & 2.03 & 2.82 & 3.48 & 2.92 & 4.03 & 2.38 & 2.11 & 2.67 \\
\hline$\sigma_{z}$ & 0.1 & invg & 2 & 41.63 & 34.39 & 48.87 & 66.82 & 56.07 & 77.78 & 50.58 & 44.95 & 55.91 \\
\hline
\end{tabular}

Table C.1: Estimation Results - First Specification 


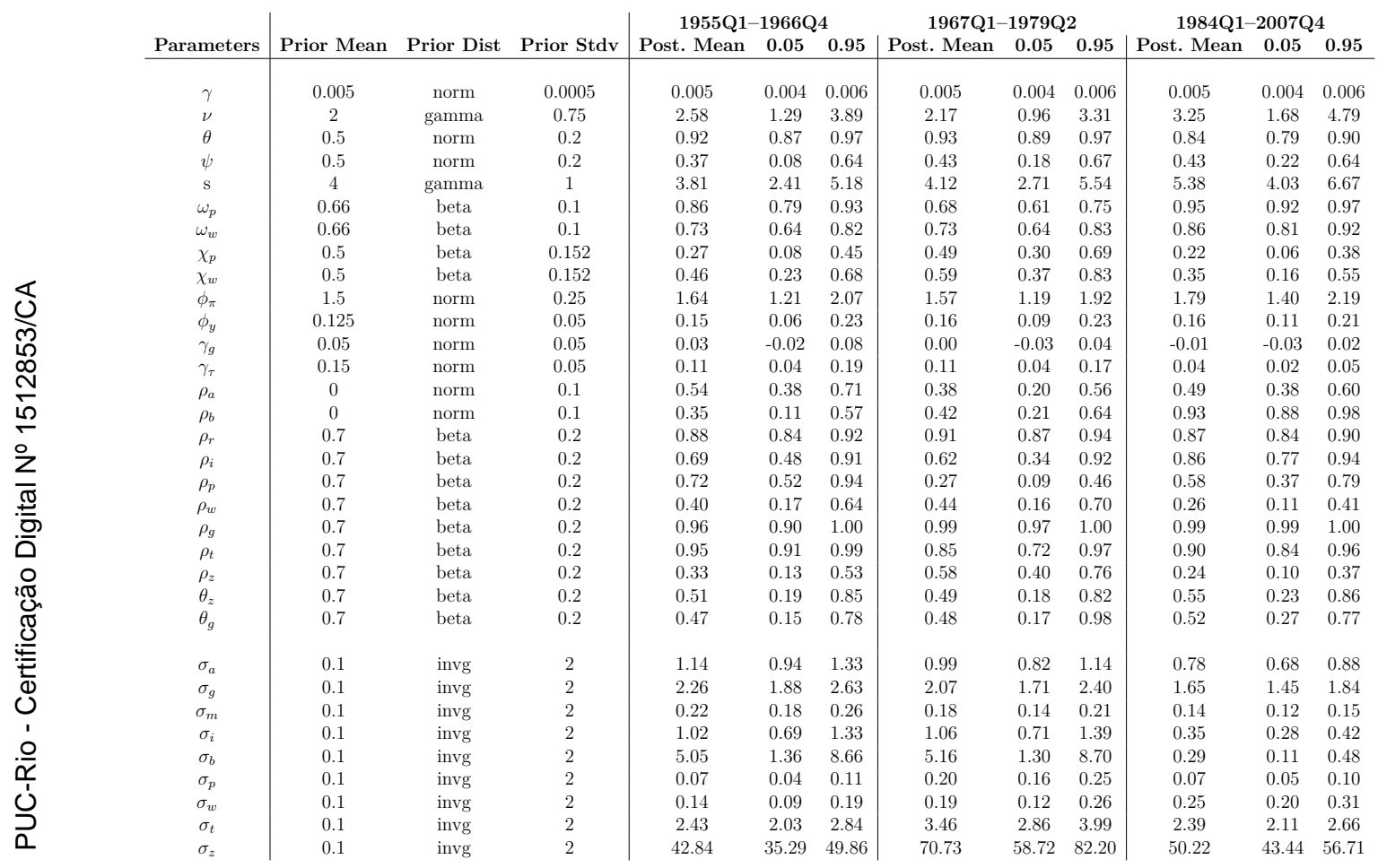

Table C.2: Estimation Results - Second Specification 